\title{
STRAIN-INDUCED CRYSTALLIZATION OF NATURAL RUBBER: A REVIEW OF X-RAY DIFFRACTION INVESTIGATIONS
}

\author{
BERTRAND HUNEAU \\ LUNAM UNIVERsité, ECOLE CENTRALE de NANTES, INSTITUT DE RECHERCHE EN GÉNIE CIVIL ET MÉCANIQUE \\ (GEM), UMR CNRS 6183, BP 92101, F-44321 NANTES CEDEX 3, FRANCE
}

\begin{abstract}
Strain-induced crystallization of natural rubber was discovered in 1925 by the means of x-ray diffraction and has been widely investigated by this technique until today. The studies devoted to the structure of the crystalline phase of natural rubber are first reviewed. This structure is strongly anisotropic and can be related to the exceptionally good strength and fatigue properties of this material. The relationships between strain-induced crystallization of natural rubber and its mechanical response, during static or tension-retraction tests, are also reviewed and discussed; in particular, the hysteresis of the stress-strain curve is mainly explained by strain-induced crystallization. The kinetics of crystallization under both static and cyclic deformation is also discussed, as well as the influence of different factors, depending either on material composition (crosslink density, carbon black fillers) or on external parameters (temperature, strain rate... )
\end{abstract}

\section{INTRODUCTION}

Natural rubber (NR), cis-1,4-polyisoprene, is a widely used material in elastomeric parts because it combines very large elastic strain with a high tensile strength and a remarkable crack growth resistance. ${ }^{1,2}$ These outstanding properties are partly attributed to the strain-induced crystallization (SIC) phenomenon that occurs in NR. In particular, the induced crystallites are supposed to slow down, deviate, and even stop crack growth, either for static or cyclic loading conditions. ${ }^{3}$ This ability to crystallize under strain is often explained by the high regularity of 
the macromolecular structure, i.e., its percentage of chains being in cis-configuration, which is very close to $100 \%$ in NR. Synthetic isoprene rubber (IR) exhibits a lower crystallinity than NR because of the lower regularity of the macromolecular structure, even though it can contain more than $98 \%$ of chains in cis-configuration. Some authors also argue that the non-rubber components in NR (6 wt. \% of proteins and lipids) play a major role in its excellent mechanical properties, because they enhance its capacity to crystallize. ${ }^{4,5}$

SIC was discovered in 1925 by Katz, ${ }^{6}$ who was the first to show the x-ray diffraction pattern of a uniaxially stretched NR. Note that unstrained NR can also crystallize by cooling; this phenomenon is called thermally induced crystallization (TIC), or "cold" crystallization and was studied for example by Bekkedahl and Wood in the 1940s. ${ }^{7,8}$ They used the volume change technique to study the kinetics of this kind of crystallization. In particular, they established that the maximal crystallization rate of unstretched rubber takes place at approximately $-25{ }^{\circ} \mathrm{C}$, whereas at room temperature no crystallization occurs.

Many experimental techniques were used over the years to investigate the crystallization of NR under strain: volume change ${ }^{7-10}$ stress relaxation, ${ }^{9}$ transmission electron microscopy, ${ }^{11,12}$ differential scanning calorimetry, ${ }^{13}$ birefringence, ${ }^{14,15}$ nuclear magnetic resonance, ${ }^{5,16}$ or Raman spectroscopy. ${ }^{17}$ Nevertheless, the present review will be limited to wide-angle $\mathrm{x}$-ray diffraction (WAXD) studies of SIC, from the pioneering works to the most recent studies. The reader interested in theoretical and thermodynamical approaches is invited to consult the works of Flory, ${ }^{18}$ Treloar, ${ }^{19}$ or Roberts and Mandelkern. ${ }^{20}$ Moreover, one should notice that some aspects of SIC were already reviewed, for example, by Magill ${ }^{21}$ and more recently by Tosaka. $^{22}$

After the discovery of Katz, a large number of WAXD studies were performed especially during the 1930s and the 1940s. Some of them were dedicated to the crystal structure of NR, but rapidly some engineering studies investigated more deeply SIC of NR. In the last 10 years, this topic has been updated by the use of synchrotron radiation, which permits to perform real-time experiments. In Section II, the crystal structure of NR and its lattice parameters will be presented, as well as the crystallites morphology. In Section III, the relationships between SIC and the mechanical response of NR will be detailed especially during a tension-retraction cycle. Finally, Section IV will present different factors that affect SIC.

\section{THE CRYSTALLINE PHASE OF NATURAL RUBBER}

\section{A. CRYSTALLOGRAPHIC STRUCTURE}

The crystal structure and the lattice parameters of strain-induced crystallized NR can be deduced from the x-ray diffraction pattern. Figure 1 gives a typical example of a diffraction pattern that can be obtained when x-ray beam is perpendicular to the stretched sample. ${ }^{23}$ Among the most intense diffraction spots, one can distinguish the ones that are due to crystallographic planes (200), (120), and (002). The position of the spots gives the distance $d_{h k l}$ between (hkl) planes, by using the Bragg law

$$
d_{h k l}=\frac{n \lambda}{2 \sin \theta}
$$

where $n$ is a strictly positive integer, $\lambda$ is the wavelength of the $\mathrm{x}$-ray, and $\theta$ is the diffraction angle (also called Bragg angle) of the spot due to (hkl) planes.

The structure and the lattice parameters of NR were first reported in 1928 by Mark and von Susich. ${ }^{24}$ They proposed an orthorhombic structure with $a=12.3 \AA, b=8.3 \AA$, and $c=8.1$ $\AA$. At the same period, Meyer and Mark ${ }^{25}$ suggested that NR is the cis-form of polyisoprene 


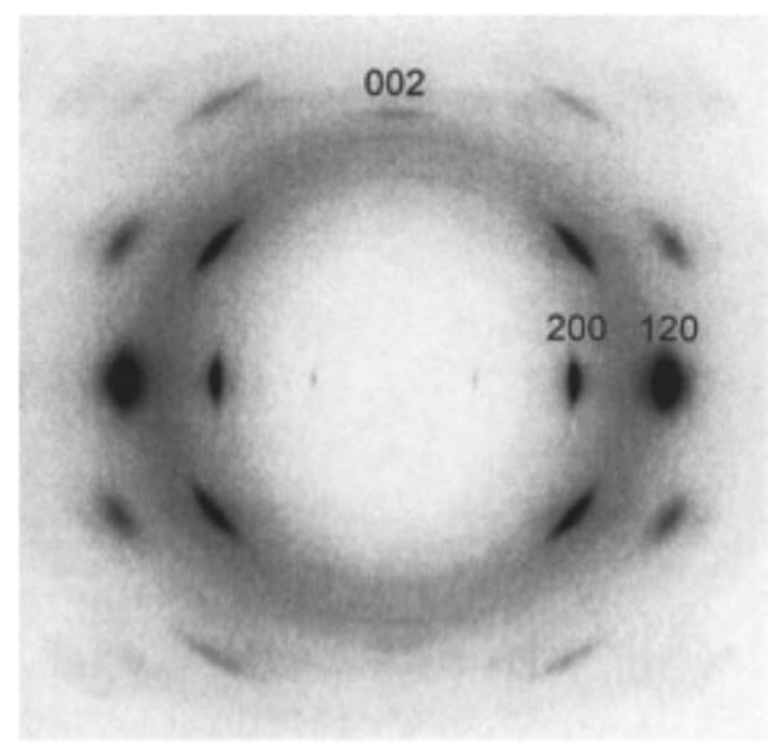

FIG. 1. - Typical WAXD pattern of a vulcanized NR stretched up to 7.35 times its original length; the stretching direction is vertical. (Reprinted from ref 23. Copyright 2004 Rubber Division, American Chemical Society.)

whereas the trans-form corresponds to Gutta Percha rubber. Later, the molecular structure of NR was discussed by Lotmar and Meyer, ${ }^{26}$ Sauter, ${ }^{27}$ and Morss,${ }^{28}$ who proposed various lattice parameters either in monoclinic or orthorhombic structure; the only difference between these two systems being the $\beta$ angle, which is equal to $90^{\circ}$ in the orthorhombic system. Detailed review articles on this subject were published in 1939 and 1940 by Clark $^{29}$ and Gehman, ${ }^{30}$ respectively. These authors pointed out that vulcanization of rubber does not affect its ability to crystallize. The diffraction patterns of vulcanized and unvulcanized NR are very similar as shown in the work of Gehman and Field, ${ }^{31}$ who also demonstrated that the crystal structure is not changed in NR vulcanizates containing carbon black fillers. ${ }^{32}$ The influence of crosslinking and fillers on SIC will be detailed in Section IV of the present article. In 1942, Bunn ${ }^{33}$ published one of the most significant work on the crystallographic structure of NR. His detailed study gave evidence to the monoclinic structure containing four chains per unit cell and with the following parameters: $a$ $=12.46 \AA, b=8.89 \AA, c=8.10 \AA$ and $\beta=92^{\circ}$. As shown in Figure 2, macromolecules are oriented along the $c$-axis of the crystal cell. Each cell contains four chains, which correspond to eight monomers. When SIC takes place in uniaxial tension, the $c$-axis corresponds to the stretching direction. The active chemical bonds in this direction are strong because they are covalent; on the contrary, active bonds in the basal plane (001) are weaker (Van der Waals bonds). It leads to an important anisotropy of the macromolecular structure. The excellent mechanical properties of NR are generally attributed to the alignment of macromolecules in the stretching direction that strengthen the material. Among the few studies published in the 1950s, one can cite the work of Nyburg, ${ }^{34}$ who proposed a statistical replacement of equivalent molecular chains with mirror symmetry. Natta and Corradini ${ }^{35}$ reinterpreted Nyburg's data and claimed for an orthorhombic cell. Later, Mitchell ${ }^{36}$ presented a quantitative study of SIC in NR crosslinked with peroxide, and proposed a method to evaluate the degree of crystallinity. In the last few years, the debate concerning the crystallographic structure of NR was revived. The monoclinic structure of NR crystal was first confirmed by Takahashi and Kumano ${ }^{37}$ who refined the values of the lattice parameters provided by Bunn. The work of Takahashi and Kumano was then 


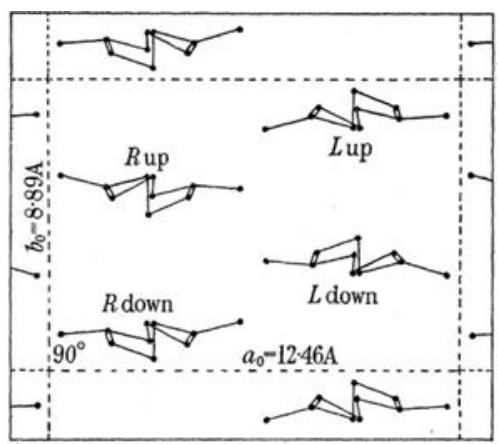

(a)

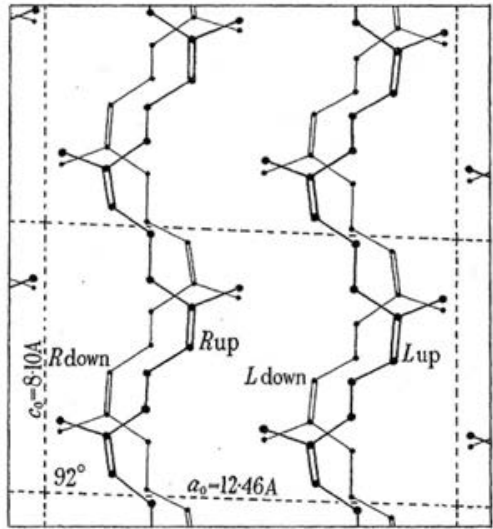

(b)

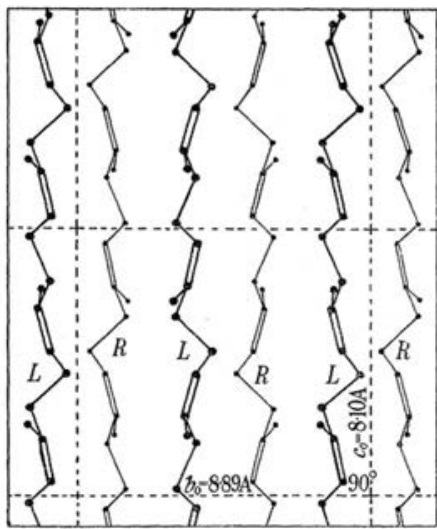

(c)

FIG. 2. - The crystal structure of NR seen along: (a) $c$-axis, (b) $b$-axis, and (c) $a$-axis. (Reprinted with permission from ref 33. Copyright 1942 Royal Society Publishing.)

questioned by Immirzi et al. ${ }^{38}$ who argued that rejection of orthorhombic cell is not justified. Finally, a recent study by Rajkumar et al., ${ }^{39}$ based on a statistical approach called "linkedatom-least-squares," 40 claimed in favor of orthorhombic cell. However, even if the debate about NR crystal is not closed, the relationships between stretching and crystallization of NR can be investigated.

Concerning the evolution of the crystal cell size during a tensile test, Poompradub et al. ${ }^{41,42}$ recently studied the evolution of the lattice parameters with loading. Figure 3 shows that lattice parameters $a$ and $b$ slightly decrease as the load increases, whereas the lattice parameter $c$ slightly increases. This phenomenon is all the more important that NR is filler free. Nevertheless, it should be kept in mind that these variations are very small (about $1 \%$ maximum). Considering this, the lattice parameters of the NR crystal cell will not be examined further. The next section will focus on the morphology of NR crystallites and also on their size and orientation, that are more relevant variables to be considered in the studies devoted to SIC of NR.

\section{B. CRYSTALLITES MORPHOLOGY}

Most of the observations concerning the morphology of rubber were performed with transmission electron microscope (TEM) on samples cooled around $-25{ }^{\circ} \mathrm{C}^{11,43-45}$ which is the 

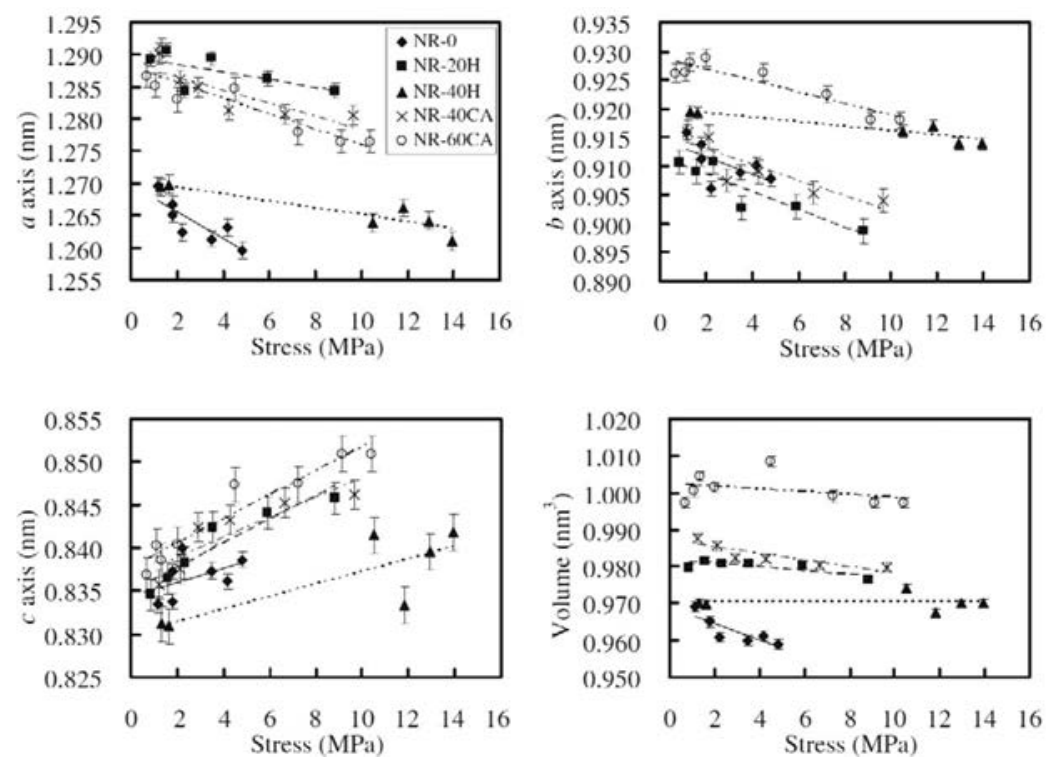

FIG. 3. - Lattice parameters and volume of the unit cell as a function of nominal stress. (Reprinted with permission from ref 42. Copyright 2005 American Institute of Physics.)

temperature that corresponds to the maximum rate of crystallization of unstretched rubber. ${ }^{8}$ In these conditions, the spherulitic structure of unstretched rubber evolves under strain to a "shishkebab" structure (strain around 100\%) and then to fibrils (strain $>300 \%$ ) aligned with the stretching direction. ${ }^{11}$ This lamellar-fibrillar transition was widely studied by Luch and Yeh. ${ }^{12}$ Concerning SIC at room temperature, these authors observed a fibrillar structure for NR with a crystallites size around $100 \AA$ A. They also investigated the morphology of NR vulcanizates by small-angle x-ray diffraction: at room temperature, highly strained (700\%) samples exhibit no discrete peaks at small angles, which is interpreted as the absence of a lamellar structure. ${ }^{46}$ However, some authors still assume the coexistence of both lamellar and fibrillar structure for SIC at room temperature. ${ }^{22,47}$

Concerning the size and the orientation of crystallites, they can be deduced from the x-ray diffraction pattern (see Figure 1); the size of the crystallites $l_{h k l}$, in the direction perpendicular to the (hkl) plane, is given by the Scherrer law

$$
l_{h k l}=\frac{K \lambda}{\mathrm{FWMH} \cos \theta}
$$

where $\lambda$ is the wavelength of the $\mathrm{x}$-ray, $K$ is a constant that depends on factors such as crystallites shape or size distribution, FWMH is the full width at half maximum for the considered diffraction peak, and $\theta$ is the Bragg angle for this peak. Considering that the most intense spots are due to planes (200), (120), and (002), crystallites size is generally given in the three directions perpendicular to those planes. The size of the crystallites will be discussed in detail in the following sections, but one can keep in mind the value of $100 \AA$ as an order of magnitude for the crystallites size in the three directions, which is consistent with TEM observations. ${ }^{12}$ The disorientation around the mean crystallites orientation is generally given by the half width at mid-height of the spots on the azimuthal profile. This value is thus an angle expressed in degrees and generally denoted $\psi_{1 / 2}$. When calculated for (002) spot, it gives the crystallites disorientation 


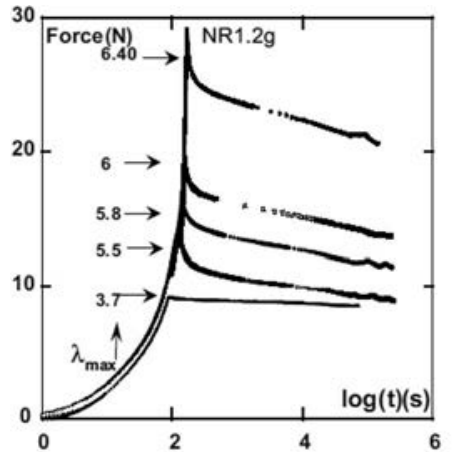

(a)

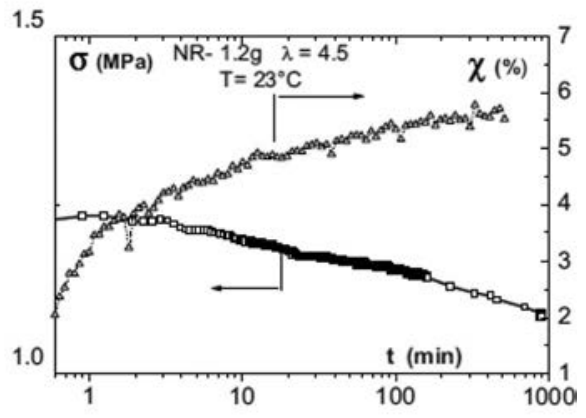

(b)

FIG. 4. - (a) Evolution of the force (in N) at room temperature vs time for a vulcanized NR (1.2 phr sulfur) for different maximum stretch ratios ( $\lambda_{\max }$ between 3.7 and 6.4); (b) evolution of stress (in MPa) and crystallinity (in\%) vs time during stress relaxation. (Reprinted with permission from ref 49. Copyright 2006 Springer.)

angle relative to the stretching direction, which generally varies from 5 to 10 degrees in unfilled NR. This result will also be detailed in the following.

\section{STRAIN-INDUCED CRYSTALLIZATION AND MECHANICAL BEHAVIOR OF NR}

Now, we consider the relationships between SIC and mechanical response of NR at room temperature. As mentioned above, many authors early suggested the beneficial effect of SIC and oriented structure of NR on its mechanical properties. ${ }^{33,48}$ The major features of SIC will be presented in this section without considering parameters such as crosslink density, effect of fillers or strain rate influence. Those parameters will be discussed in Section IV. Moreover, the methods to measure the crystallinity or at least a crystallinity index are not detailed here; but one can just say that crystallinity is generally deduced from intensities of the diffraction spots due to SIC with regard to the diffuse halo that is due to the x-ray scattering by the amorphous phase.

\section{A. DURING STATIC DEFORMATION: CRYSTALLINITY VERSUS TIME}

At room temperature, when a vulcanized NR is stretched enough to crystallize, the stress relaxes and crystallinity ( $\chi$ in $\%$ ) increases as shown in Figure $4 .{ }^{49}$ The stress relaxation curves shown in Figure 4(a) exhibit two kinetics. The first relaxation is fast (during around $100 \mathrm{~s}$ ) while the second one is slow: the stress varies linearly with the log of time and after one day the force continues to decrease. The first kinetics of stress relaxation, which remains unexplained in this work, seems to be independent on the maximum stretch ratio $\left(\lambda_{\max }\right)$, whereas the second kinetics of stress relaxation is all the more important that $\lambda_{\max }$ is high. According to the authors, the longterm stress relaxation is due to amorphous chains relaxation consecutively to crystallization, as it is predicted by Flory's theory. ${ }^{18}$ The short-term crystallization is faster during the first hundred seconds (see Figure 4(b)), similarly to the stress relaxation. However, this first step should be carefully analyzed in this study as the time to reach the maximum stretch ratio $\left(\lambda_{\max }\right)$ is very long here (around 2 minutes). The work of Choi and Roland ${ }^{50}$ on NR crosslinked with peroxide confirms this kind of evolution for stress relaxation. Similar results have been established by WAXD on NR and IR by Tosaka et al., ${ }^{51}$ who showed that SIC kinetics and consecutively stress relaxation are much slower in the case of IR. 


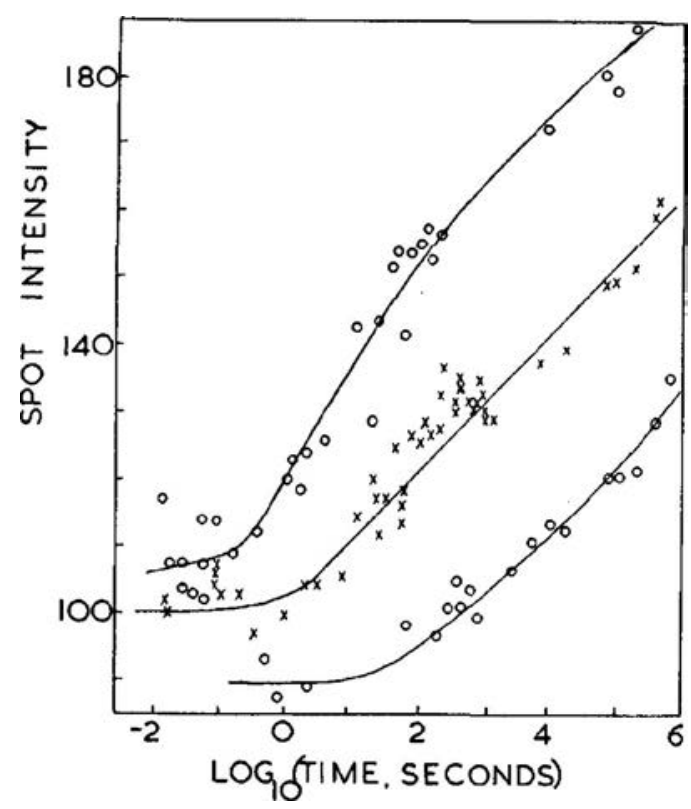

FIG. 5. - Variation of (120) spot intensity vs time, at room temperature and for three stretch ratios: $\lambda=3.62$ (bottom), $\lambda=4$ (middle), $\lambda=4.52$ (top). (Reprinted from ref 54. Copyright 1967 Rubber Division, American Chemical Society.)

The short-term crystallization for a static stretch is much more difficult to analyze than long-term crystallization because $\lambda_{\max }$ is never reached instantaneously; moreover, conventional $\mathrm{X}$-ray diffraction requires slow data acquisition (typically few minutes) that is not compatible with the study of short-time effects. Despite these problems, the early stage of SIC has been investigated by WAXD in the 1930 s by Acken et al. ${ }^{52}$ and Long et al. ${ }^{53}$ who tried to answer the following question: "Is SIC instantaneous or not?" Their studies were devoted to the first seconds of SIC and they suggested that this phenomenon requires a "time lag" to be established. In their first study, ${ }^{52}$ a very ingenious device was designed to measure this time lag; this apparatus was the first one that permits to stretch a rubber cyclically during WAXD measurements. As x-ray detectors needed to be exposed for a very long time, samples were rapidly stretched (in $0.5 \mathrm{sec}$ ) many times to a fixed stretch and maintained for a certain time (a few seconds). Thanks to a stroboscopic technique, the very weak diffracted beam was accumulated along the time. In their second study, ${ }^{53}$ authors showed that crystallization can be detected after approximately $1 \mathrm{~s}$ for $\lambda_{\max }=4.15$ (for stretching maintained approximately $5 \mathrm{~s}$ ). They concluded that the alignment of macromolecules is not instantaneous. In 1967, Dunning and Pennells ${ }^{54}$ made the same kind of experiments with another original device and performed a very precise study of SIC kinetics. Figure 5 shows the evolution of crystallinity [measured on the (120) spot] with time and for various strain levels. They suggested that a short delay exists before crystallization. The duration of this initial period before crystallization is shown to be very sensitive to the maximum stretch ratio: $18 \mathrm{~s}$ at $\lambda_{\max }=3.6,1 \mathrm{~s}$ at $\lambda_{\max }=4,130 \mathrm{~ms}$ at $\lambda_{\max }=4.5$, and $50 \mathrm{~ms}$ at $\lambda_{\max }=5$. Moreover, SIC kinetics clearly increases as $\lambda_{\max }$ increases, and crystallinity evolves almost linearly with the $\log$ of time in particular for $\lambda=4$. Nevertheless, for $\lambda>4$, the results suggest two slopes in the crystallinity versus log of time curve, as it was previously observed in Figure 4(b), which confirms a faster kinetics for short-term crystallization. One should notice that the result obtained by these authors at $\lambda_{\max }=5$ is in good agreement with the results of Mitchell and Meier ${ }^{55}$ who investigated SIC by measuring the temperature, according to the method of Votinov et al. ${ }^{56}$ 


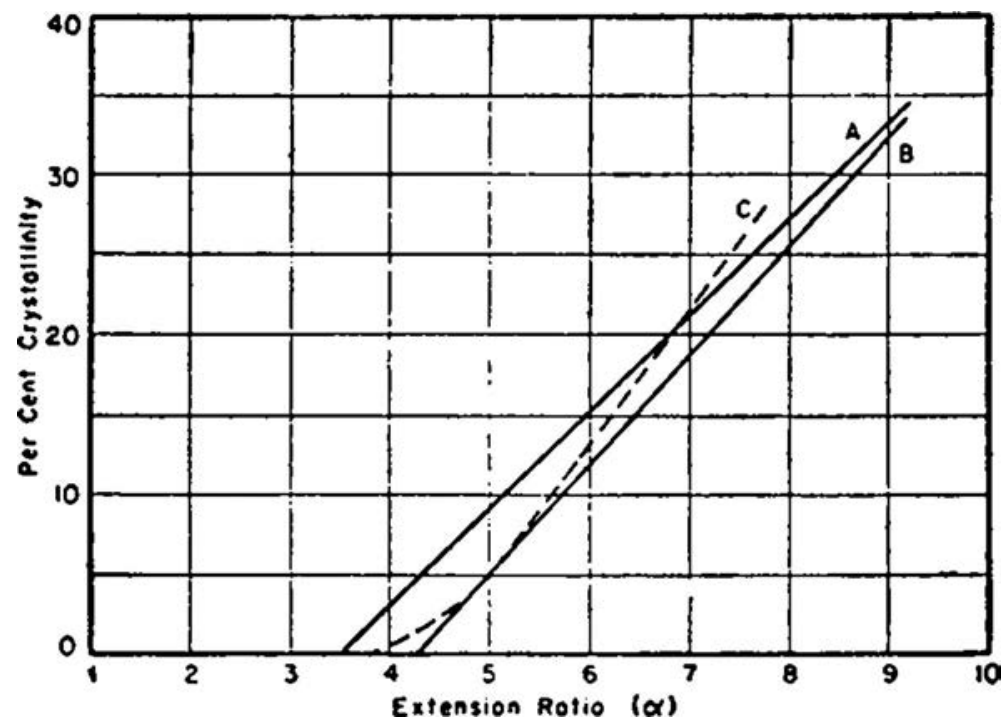

FIG. 6. - Crystallinity vs stretch ratio in vulcanized NR specimens at room temperature as measured by Alexander et al..$^{60}$ (curve A), Goppel and Arlman ${ }^{58}$ (curve B), Nyburg ${ }^{59}$ (curve C). (Reprinted with permission from ref 60.

Copyright 1955 American Institute of Physics.)

By prescribing very high strain rate, rubber samples reach the maximal stretch ratio (from $\lambda_{\max }$ $=5$ to $\lambda_{\max }=6.4$ ) in few tens of milliseconds. The authors determined that crystallization curves have time constant of approximately $50 \mathrm{~ms}$.

To conclude about SIC kinetics for NR, one can say that SIC starts quasi-instantaneously for $\lambda_{\max } \geq 4$ and the kinetics increases with $\lambda_{\max }$. Crystallinity evolves linearly with the $\log$ of time for $\lambda_{\max } \sim 4$. For higher values of $\lambda_{\max }$, it seems that two kinetics of SIC exist (a faster one followed by a slower one). Moreover, one should retain that the equilibrium of the system is never reached in all the above-mentioned studies, even after a long time ( $>1$ day).

\section{B. CRYSTALLINITY VERSUS STRETCH RATIO}

By measuring the crystallinity at different stretch ratios, the degree of crystallinity versus stretch ratio was investigated in a sequential manner, ${ }^{57-60}$ which gave the typical results shown in Figure $6{ }^{60}$ When the stretch ratio reaches a given value, the crystallinity increases almost linearly. It can be seen in this figure that the onset of crystallization for unfilled NR occurs for a stretch ratio of 4 approximately. Even if this critical value is in accordance with recent studies, ${ }^{61}$ the evolution of crystallinity should be considered with care as SIC is not stabilized during the time of the x-ray diffraction measurements.

Some studies devoted to the structure of rubber suggested that crystallites orientation depends on stretch. ${ }^{31}$ Nevertheless, if crystallites appear to be more oriented with the stretch (and also with the time), their size seems to remain constant. ${ }^{30}$ This last point is very important and was already suggested in 1926 by Hauser and Mark $^{62}$ who noticed that the "half-value width" of the spots did not change appreciably with stretch; consequently, these authors considered that the increase of crystallinity is explained by an increase in the number of crystallites rather than by an increase of their size. This idea is today widely accepted [except for the early stage of SIC (Ref. 63)]. 


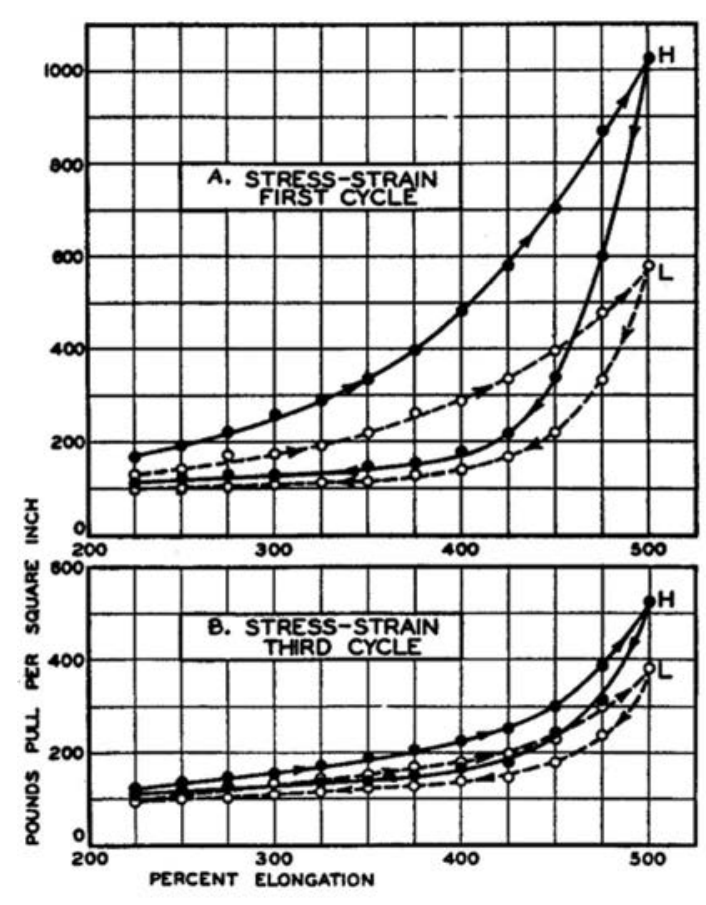

(a)

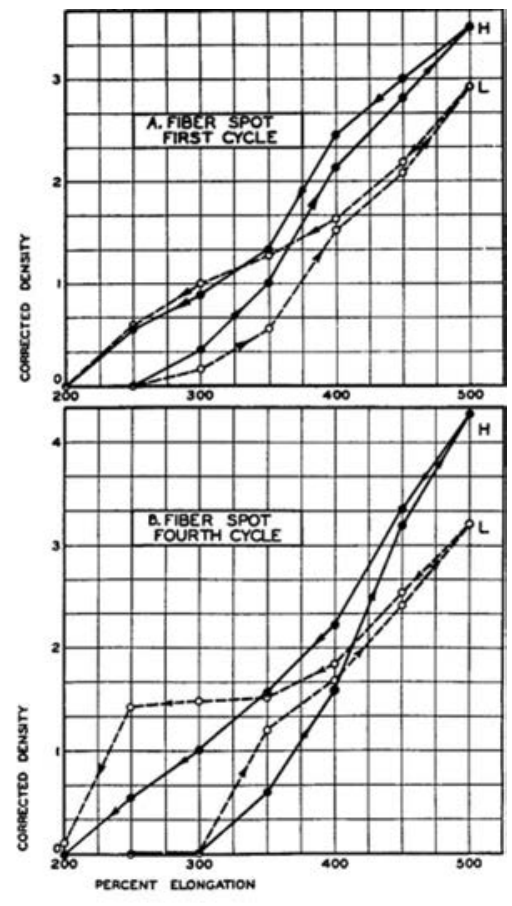

(b)

FIG. 7. - (a) Stress-strain curve for the first and the third cycle of two vulcanized NR (H: 2 phr sulfur, L: 3 phr sulfur); (b) intensity of (120) spot vs strain. (Reprinted from ref 65. Copyright 1940 American Chemical Society.)

\section{DURING A TENSION-RETRACTION TEST WITH A CONVENTIONAL X-RAY SOURCE}

The stress-strain curve of NR is known to be hysteretic for a long time (see, for example, Williams and Sturgis ${ }^{64}$ ); this hysteresis is generally more important for rubbers that exhibit SIC.

This typical feature was first related to SIC in 1940 by Clark et al. ${ }^{65}$ as shown in Figure 7. The mechanical tests were performed at a constant displacement speed of $2 \mathrm{inch} / \mathrm{min}$, whereas the WAXD measurements were made at different constant stretch ratios during one hour. Consequently, a precise correlation between the stress-strain curve and the intensity of diffraction-strain curve is not possible. However, the merit of Clark and coworkers is still to have been the firsts to suggest experimentally that the mechanical hysteresis of a tension-retraction cycle is closely related to SIC phenomenon. Treloar ${ }^{66}$ also highlighted the link between these two curves a few years later by the means of birefringence. Goppel and Arlman ${ }^{58}$ investigated more deeply the hysteresis of SIC by using the same sequential technique ( 5 min pause for WAXD measurements at each stretch ratio). They clearly showed that, for the same value of stretch ratio, the crystallinity is higher in the retraction phase than in the tension one. This kind of sequential measurements have been recently performed by Toki et al. ${ }^{47}$ Even if the detection techniques have been improved for 60 years, the exposure time to obtain the whole WAXD pattern remains too long (30 minutes) to clearly follow SIC during a mechanical test. To investigate SIC in real-time, these authors recorded the intensity of the brightest equatorial spot, i.e., the (120) spot, during a continuous tension-retraction test. With this method, Toki et al ${ }^{47}$ were the first, to the author's knowledge, to obtain simultaneously the stress-strain curve and the x-ray intensity-strain curve (see Figure 8). 


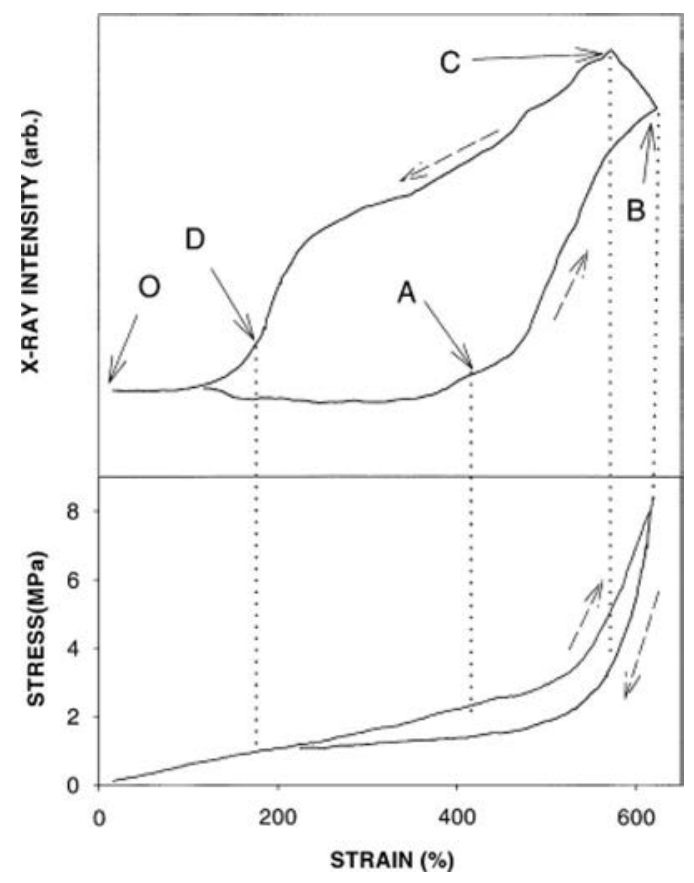

FIG. 8. - Simultaneous evolution of intensity for (120) spot (a.u.) and stress (MPa) vs strain (\%) for a vulcanized NR (1.5 phr sulfur). (Reprinted with permission from ref 47. Copyright 2000 Elsevier.)

Considering that crystallites completely melt at approximately the strain at which the stress-strain loop closes, the hysteresis of the stress-strain curve is again correlated to SIC.

All these studies illustrate the fact that conventional WAXD is maybe not the most appropriate technique to perform real-time experiments during mechanical tests on NR vulcanizates. It surely explains why other techniques, such as volume change, stress relaxation or birefringence were widely used for decades to study SIC. ${ }^{7,9,66,67}$ In the next section, we will see how the major drawback of WAXD performed with a conventional x-ray source, namely the long exposure times, can be overcome thanks to synchrotron radiation.

\section{REAL-TIME WAXD MEASUREMENTS OBTAINED WITH SYNCHROTRON RADIATION}

Thanks to the brightness of the synchrotron radiation, WAXD experiments can be made to study SIC in real-time, usually at room temperature. The first publications on this subject emerged in the early 2000s. ${ }^{61,68-71}$ A few research groups in the world are active in this field mainly in Japan and USA (with experiments performed on SPring8 synchrotron in Hyogo, Japan and on National Synchrotron Light Source at Brookhaven National Laboratory in New York, USA) ${ }^{15,23,41,42,51,68-70,72-81}$ as well as in France (with experiments performed at LURE, Orsay and ESRF, Grenoble). ${ }^{16,49,61,63,71,82-84}$

Figure 9 presents an example of a stress-strain curve with the corresponding WAXD pattern obtained on a vulcanized NR at room temperature. ${ }^{73}$ Toki and coworkers consider that stretched rubber can be decomposed into three phases: (i) an unoriented amorphous phase, (ii) an oriented amorphous phase, and (iii) a crystalline phase. They used the method developed by Ran et al. ${ }^{85}$ to analyze their diffraction patterns. The complete analysis procedure to evaluate the mass fraction of each phase is detailed in Toki et al. ${ }^{73}$ Thanks to this procedure, they followed the evolution of 


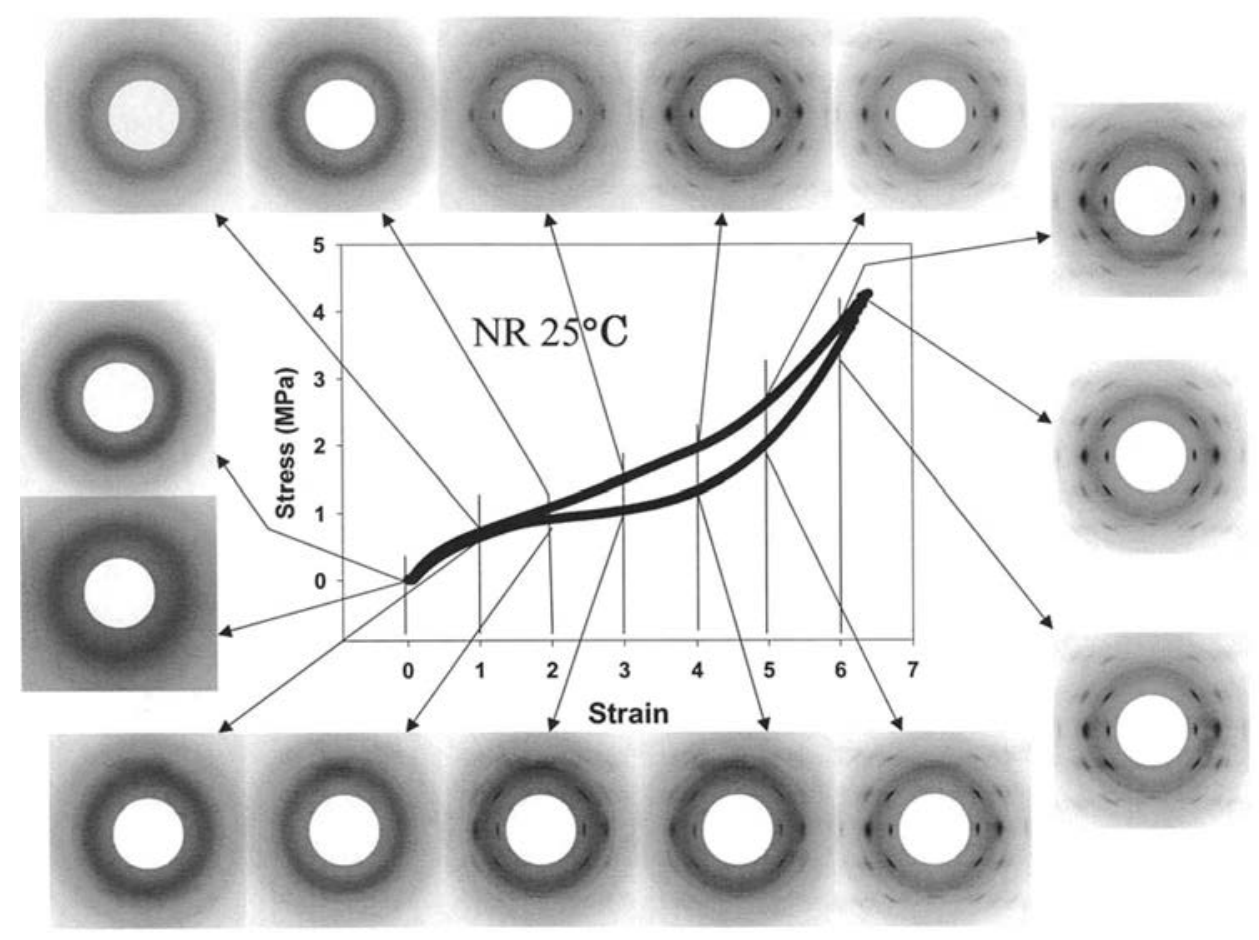

FIG. 9. - Stress-strain curve and corresponding diffraction patterns recorded simultaneously for a vulcanized NR (1.5 phr sulfur). (Reprinted from ref 73. Copyright 2004 Rubber Division, American Chemical Society.)

the crystalline phase and of both unoriented and oriented amorphous phases during the tensionretraction cycle as shown in Figure 10. These authors generally explain SIC by the heterogeneity of vulcanization ${ }^{70,73}$ according to Göritz and Grassler. ${ }^{13}$ This assumption led Tosaka et al..$^{23}$ to propose the molecular model presented in Figure 11: they consider that the number of monomers between two crosslinks is not constant, which means that some macromolecular chains are shorter than others; during loading, the shorter chains are fully stretched at first and subsequently become nucleation sites for crystallites.

Similar experiments have been conducted at the same time in France with comparable crosslinked natural rubbers. Figure 12 shows the corresponding stress-strain and crystallinitystrain curves. These curves were obtained for a very low travel speed $(1 \mathrm{~mm} / \mathrm{min}$, strain rate $\sim 5 \times 10^{-4} \mathrm{~s}^{-1}$ ). Figure 12(b) clearly highlights the difference in critical stretch ratios for crystallization and melting; this feature is called "supercooling effect" by Trabelsi et al. ${ }^{61}$ Both curves are analyzed as follows:

- Crystallization starts at point A (around $\lambda=4$ ). The crystallites are then growing. Each crystallite acts as a new crosslink and stiffens the material (hardening). Simultaneously, amorphous chains relax, as proposed by Flory. ${ }^{18}$ These two opposing effects tend to offset each other, producing a plateau.

- At point B, crystallization kinetics increases, which leads to an important hardening of the material. Note that this interpretation is not in accordance with the idea of considering the finite extensibility of chains as responsible for this important hardening. Rault and coworkers justify this conclusion by observing a significant reduction in stiffness at 


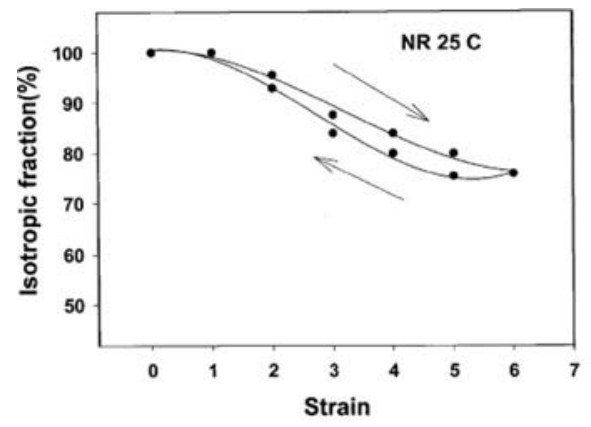

(a)

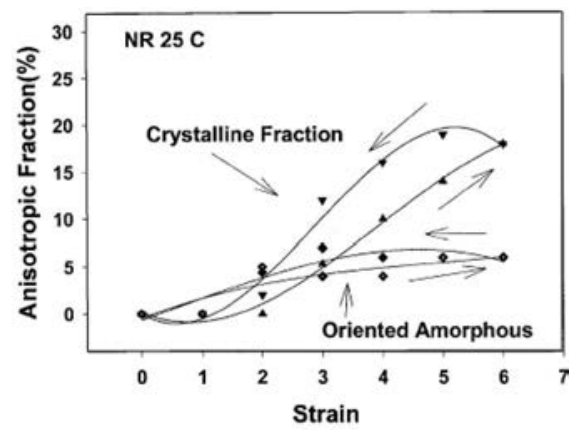

(b)

FIG. 10. - Variations of the fraction of: (a) unoriented amorphous phase, (b) oriented amorphous and crystalline phases vs strain for a vulcanized NR (1.5 phr sulfur). (Reprinted from ref 73. Copyright 2004 Rubber Division,

American Chemical Society.)

$80{ }^{\circ} \mathrm{C}$, a temperature at which they consider there is no more crystallization in the material.

- As soon as retraction begins, i.e., from point $\mathrm{C}$, crystallites start to melt. For a given $\lambda$, the stress during the retraction is smaller than the corresponding one in tension, while the crystallinity is higher (hysteresis on both curves). This fact confirms and makes more precise the observations of Clark et al. ${ }^{65}$ and of Goppel and Arlman. ${ }^{58}$ The fact that crystallinity is higher during retraction than during tension is attributed to the "supercooling effect" (the difference in critical stretch ratios for crystallization and melting).

- From point D, the stress is almost constant. Melting of crystallites still exists but amorphous chains become more extended; this was confirmed by nuclear magnetic resonance

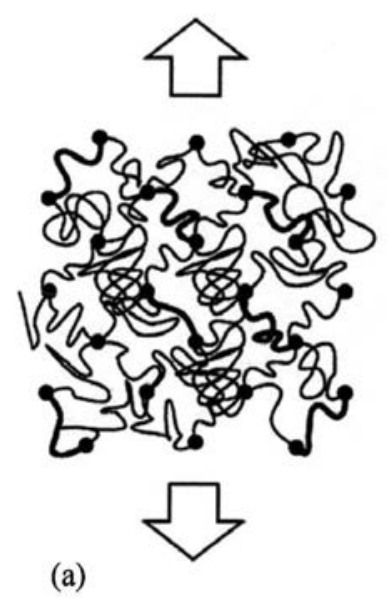

(b)

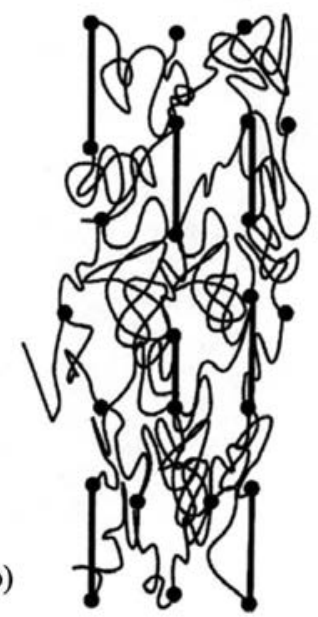

(c)

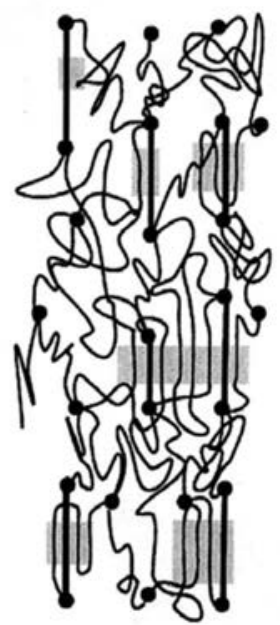

FIG. 11. - SIC model proposed by Tosaka et $a l .^{23}$ for crosslinked NR. Relatively short chains are drawn as thick lines. Filled circles represent crosslinks. (a) Before deformation. (b) After deformation just before the onset crystallization. (c) The fully stretched chains have acted as nucleus of crystallites (shaded parts). (Reprinted from ref 23. Copyright 2004 Rubber Division, American Chemical Society.) 


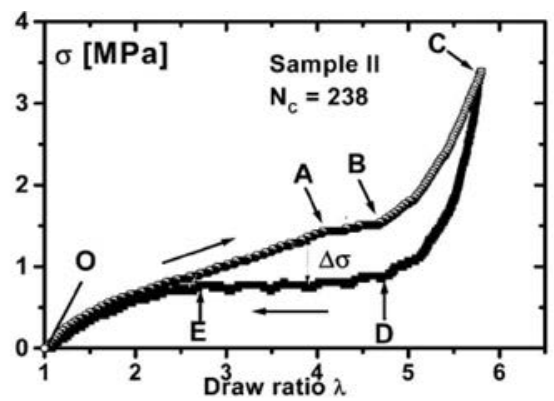

(a)

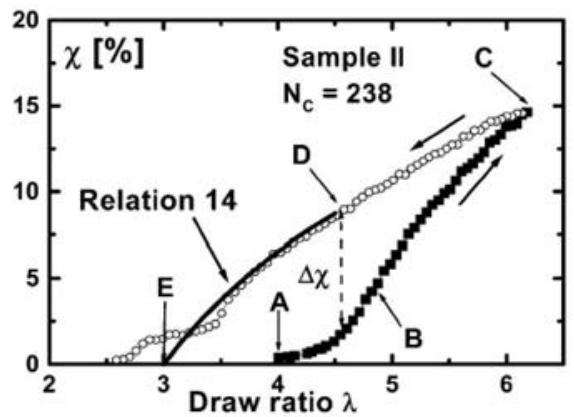

(b)

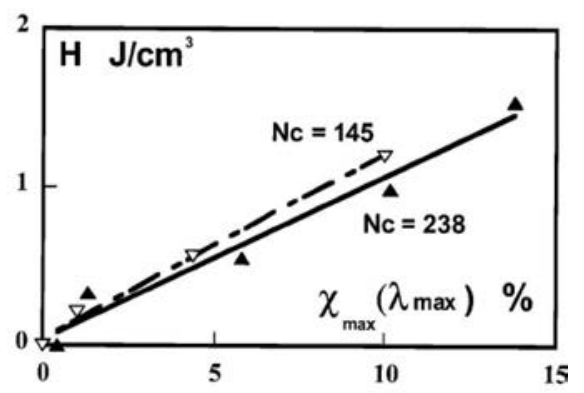

(c)

FIG. 12. - Simultaneous evolution of: (a) stress and (b) crystallinity vs stretch ratio, during a tension-retraction cycle (strain rate $\sim 5 \times 10^{-4} \mathrm{~s}^{-1}$ ) at $22{ }^{\circ} \mathrm{C}$ for a vulcanized NR (1.2 phr sulfur). (c) Evolution of the mechanical hysteresis vs the maximum crystallinity measured at the maximum stretch ratio for different samples of two vulcanized NR containing: $1.2 \mathrm{phr}$ sulfur (black triangles), $2 \mathrm{phr}$ sulfur (white triangles). (Reprinted from ref 61. Copyright 2003 American Chemical Society.)

(NMR) studies. ${ }^{49}$ Once again, these two effects offset each other (as between point A and B). Last crystallites melt at point E.

One of the major conclusions of this work is that the mechanical hysteresis is mainly due to SIC. This point is highlighted in Figure 12(c) that shows the mechanical hysteresis $\mathrm{H}\left(\mathrm{in} \mathrm{J} / \mathrm{cm}^{3}\right)$ obtained for tests performed at different $\lambda_{\max }$ as a function of the maximum crystallinity $\chi_{\max }$ reached for each value of $\lambda_{\max }$. Considering this relation, these authors considered the contribution of the viscoselastic properties on the mechanical hysteresis as negligible. This research team did not consider the oriented amorphous phase in their WAXD studies, ${ }^{61,71,82}$ but they investigated 


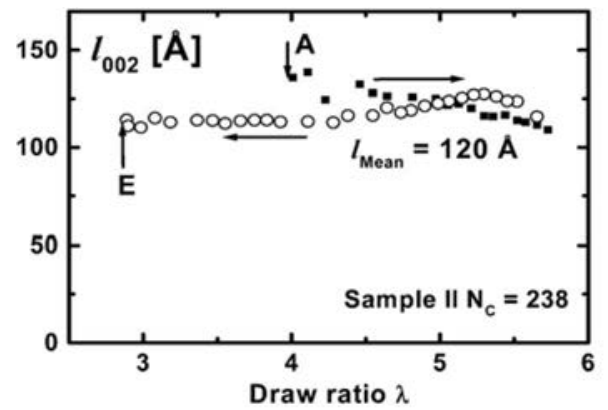

(a)

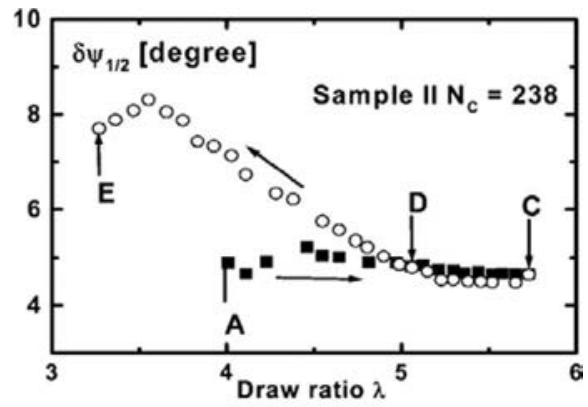

(b)

FIG. 13. - Evolution of crystallites: (a) size $\left(l_{002}\right)$ and (b) disorientation along $c$-axis at $23{ }^{\circ} \mathrm{C}$ for a vulcanized NR $(1.2$ phr sulfur) vs stretch ratio. (Reprinted from ref 61. Copyright 2003 American Chemical Society.)

it through NMR studies. ${ }^{16,49}$ The latter studies show that a part of the macromolecules become more and more aligned during stretching until SIC starts, which makes sense if one considers that macromolecules need to be aligned to crystallize. During crystallization the amorphous chains alignment remains roughly constant.

Among the above-mentioned studies, some of them contain data about the evolution of crystallites size and orientation during one mechanical cycle. The size of crystallites was measured by Trabelsi et al. ${ }^{61}$ along (002) direction corresponding to the stretching direction or along (200) and (120) directions by Tosaka et al. ${ }^{72}$ or along those three directions by Chenal et al. ${ }^{63,84}$ According to the latter authors, the dimensions of crystallites for a NR containing $1.5 \mathrm{phr}$ sulfur and stretched at $\lambda=5$ at room temperature are approximately: $l_{200}=100 \AA, l_{120}=30 \AA$ and $l_{002}$ $=90 \AA .84$

As shown in Figure 13, crystallites size in the stretching direction $\left(l_{002}\right)$ is rather constant during the whole cycle. ${ }^{61}$ This was confirmed by Chenal et al ${ }^{84}$ on NR samples having different network chain density (constant sulfur content, variable CBS content). The evolution of crystallites size along the two other directions is not so clear. Tosaka et al. ${ }^{72}$ found that $l_{200}$ and $l_{120}$ decrease during stretching whereas Chenal et al. obtained the opposite result: in their study, crystallites seem to grow during stretching till $\lambda=5$. Even if these results are contradictory with the previous ones, an increase of crystallites volume would not completely explain the increase of crystallinity. Consequently, from all studies, it can be concluded that the increase of crystallinity is mainly due to an increase of the number of crystallites, as proposed earlier by Hauser and Mark. ${ }^{62}$ SIC is thus mainly governed by nucleation rather than by growth of crystallites.

As seen in Figure 13(b), crystallites disorientation along the $c$-axis, i.e., in (002) direction, is around $5^{\circ}$ during tension and remains constant. During retraction, there is an additional disorientation: crystallites are slightly disoriented before melting. ${ }^{61}$ Tosaka et al. ${ }^{72}$ observed exactly the same trend for the orientation along the (200) direction, which suggests that the crystallites are more disoriented during the retraction in all directions. This can be easily understood by recalling that crystallites are less constrained in space during retraction.

Now that we know more about SIC, the influence of other key parameters (depending on experimental conditions) is reviewed in the next section. 

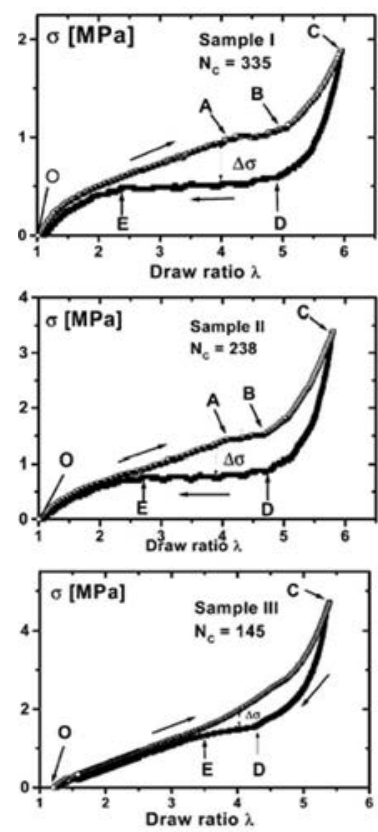

(a)
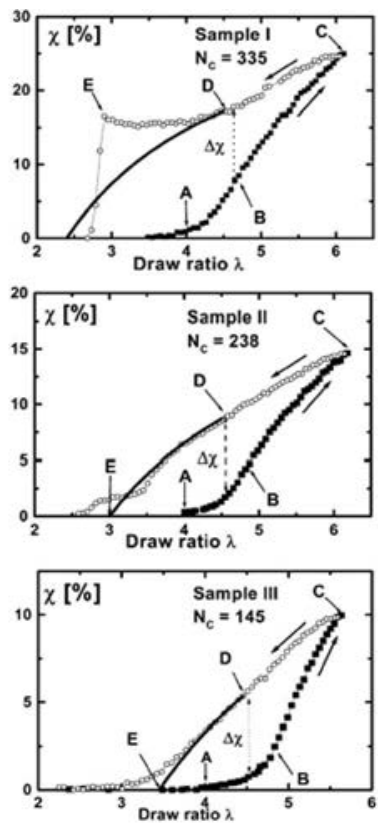

(b)
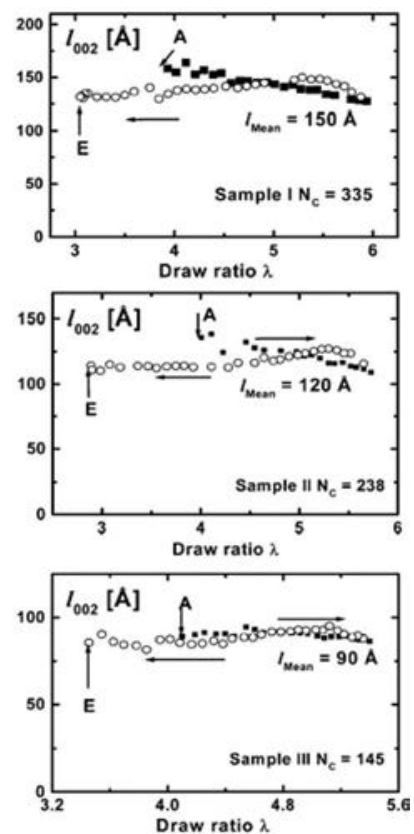

(c)

FIG. 14. - Influence of crosslink density on: (a) stress, (b) crystallinity, and (c) crystallites size $\left(l_{002}\right)$ as a function of stretch ratio (samples I, II, and III contain $0.8,1.2$, and 2 phr sulfur and have a crosslink density of $0.40,0.57$, and 0.94 $\times 10^{4} \mathrm{~mol} / \mathrm{cm}^{3}$, respectively). (Reprinted from ref 61. Copyright 2003 American Chemical Society.)

\section{FACTORS THAT AFFECT STRAIN-INDUCED CRYSTALLIZATION}

\section{A. CROSSLINK DENSITY}

The influence of crosslink density ( $\nu$, expressed in $\mathrm{mol} / \mathrm{cm}^{3}$ ) on SIC was studied by many authors $^{23,61,63,72,84}$ but it is still not entirely understood. The first interesting result is that the stretch ratio for onset of crystallization $\left(\lambda_{\mathrm{A}}\right.$ according to Figure 12) is almost unchanged with crosslink density, which is not so easy to admit considering the classical rubber elasticity theory. ${ }^{19}$ Tosaka $^{22}$ assumed that this result could be related to the heterogeneity of the rubber network structure.

Trabelsi et al. ${ }^{61}$ studied the influence of crosslink density by using three different sulfur contents: $0.8 \mathrm{phr}$ (sample I), $1.2 \mathrm{phr}$ (sample II), and $2 \mathrm{phr}$ sulfur (sample III). Crosslink density increases with the amount of sulfur (from approximately 0.4 to $1 \times 10^{4} \mathrm{~mol} / \mathrm{cm}^{3}$ ) and is inversely proportional to the number of monomers between each crosslink $\left(\mathrm{N}_{\mathrm{c}}\right)$. Figure 14 presents, for the three materials: the tension-retraction cycle (Fig. 14(a)), the crystallinity evolution (Fig. 14(b)), and the crystallites size evolution along the stretching direction (Fig. 14(c)). Figures 14(a) and 14(b) confirm that $\lambda_{\mathrm{A}}$ is almost independent on the crosslink density. The comparison between the three mechanical hysteresis is difficult on the basis of these curves considering that they are not plotted with the same scales. However, assuming that $\lambda_{\mathrm{A}}$ does not depend on $v$, the values of the crystallinity $\chi$ for a given $\lambda$, as well as the crystallinity rates $(\mathrm{d} \chi / \mathrm{d} \lambda$, i.e., the slope of the curve crystallinity versus stretch ratio), can be compared to evaluate the intensity of SIC during stretching. For a given value of $\lambda$, the less crosslinked NR (sample I) has clearly the highest crystallinity and the highest crystallinity rate. Concerning the two other NR samples (samples II and III), they exhibit similar $\chi$ for a given $\lambda$ (for example, $\chi$ is about $10 \%$ at $\lambda=5.5$ ) and 


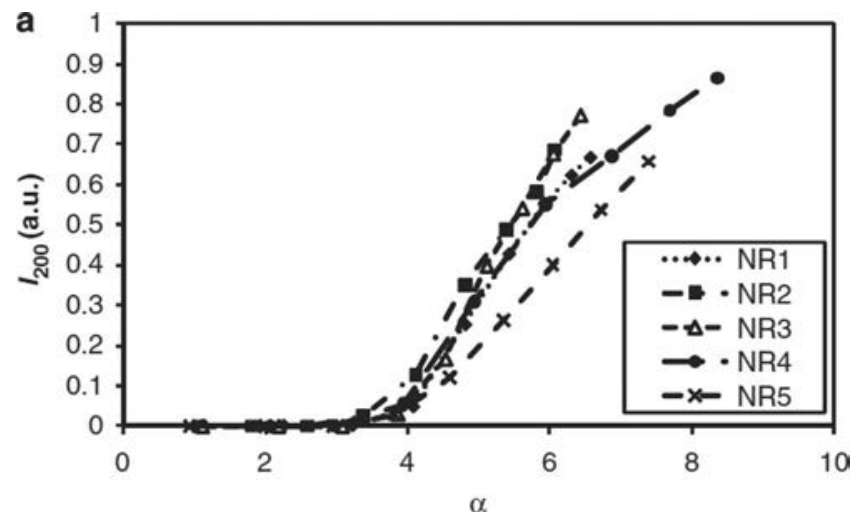

FIG. 15. - Influence of crosslinking on the intensity of (200) spot for vulcanized NR samples: crosslink density is $2.12,1.78,1.46,1.31$, and $1.01 \times 10^{4} \mathrm{~mol} / \mathrm{cm}^{3}$ for samples NR1, NR2, NR3, NR4, and NR5, respectively. (Reprinted with permission from ref 15 . Copyright 2010 The Society of Polymer Science.)

equivalent crystallinity rates. Nevertheless, the critical stretch ratio for which the last crystals melt $\left(\lambda_{E}\right)$ being higher for sample III, the authors concluded that SIC is lowered when crosslink density increases. They also noticed that crystallites size in the stretching direction (Fig. 14(c)) decreases as the crosslink density increases. This reduction in size was confirmed by other studies in which it was also observed in the other directions. ${ }^{23,63,84}$ This can be explained by considering that macromolecular chains are all the more shorten that crosslink density increases. Consequently, their ability to move in order to produce big crystallites is lowered. Trabelsi et al ${ }^{61}$ suggest that crosslinks play the same role than entanglements and limit both SIC and crystallites size: for lower crosslinked NR, the crystallinity is higher because the longer chains between crosslinks can form larger crystallites (in the stretching direction), and we can assume that their volume evolves the same way. For the two other samples, if we consider that crystallites size and volume are reduced for the most crosslinked sample (sample III), it induces a large number of crystallites since crystallinity (related to volume fraction of the crystalline phase) is comparable in both samples. Consequently, one can reasonably conclude from this study that an increase in crosslink density increases the number of crystallites and reduces their volume.

Concerning the effect of crosslink density on SIC, Tosaka et al. ${ }^{23}$ first obtained results on vulcanized NR that seem to be contradictory with the ones of Trabelsi and coworkers. They plotted the crystallinity versus stretch ratio for five NR vulcanizates, with crosslink density varying approximately from 1 to $2 \times 10^{4} \mathrm{~mol} / \mathrm{cm}^{3}$, and concluded that SIC is all the more important that crosslink density is high. Very recently, they have reconsidered their initial data and they plotted again crystallinity as a function of stretch ratio as shown in Figure $15 .{ }^{15}$ NR1 is the rubber with the highest crosslink density, whereas NR5 is the one with the lowest crosslink density. This curve suggests that both maximum crystallinity and maximum crystallinity rate are larger for the intermediate crosslink density NR3 sample $\left(1.46 \times 10^{4} \mathrm{~mol} / \mathrm{cm}^{3}\right)$. Moreover, Tosaka et al. ${ }^{72}$ observed a decrease in crystallites size as the crosslink density increases. This would suggest that maximum crystallinity, i.e., the maximum volume fraction of crystallites, is reached for an optimal combination of number of crystallites and volume of each crystallite.

The existence of an optimal crosslink density for the SIC of vulcanized NR was already suggested by Chenal et al. ${ }^{63,84}$ For highly crosslinked NR (from 1.61 to $1.95 \times 10^{4} \mathrm{~mol} / \mathrm{cm}^{3}$ ), they clearly established that SIC decreases as the crosslink density increases. ${ }^{84}$ This result is in good agreement with the one of Tosaka et al. ${ }^{15}$ in the same range of crosslink density. Chenal and coworkers showed that SIC diminution is associated with an important reduction of the crystallites 
volume: from $290 \mathrm{~nm}^{3}$ for $v=1.61 \times 10^{4} \mathrm{~mol} / \mathrm{cm}^{3}$ to $130 \mathrm{~nm}^{3}$ for $v=1.95 \times 10^{4} \mathrm{~mol} / \mathrm{cm}^{3}$. They also considered the case of a very low crosslinked NR $\left(0.25 \times 10^{4} \mathrm{~mol} / \mathrm{cm}^{3}\right)$ that exhibits a low crystallinity rate. Considering these results, they proposed an optimal crosslink density of about $1.2 \times 10^{4} \mathrm{~mol} / \mathrm{cm}^{3}$.

To close this discussion and by considering all the above-mentioned studies, the author of the present review proposes the following conclusions for crosslink density greater than 1 $\times 10^{4} \mathrm{~mol} / \mathrm{cm}^{3}$ :

- nucleation of crystallites is supposed to be governed by the local stretch ratio of the macromolecules, and thus it increases as crosslink density increases,

- the maximum crystallites size is governed by chain length between two crosslinks, and consequently it decreases as crosslink density increases. Moreover, SIC is assumed to disappear if crosslink density is too high (the crystallites volume would tend towards zero),

- $\quad$ an optimal crosslink density exists for SIC; it corresponds to a relatively high number of crystallites associated to a large crystallites volume, the product of these two values being proportional to crystallinity. The existence of an optimal crosslink density of approximately $1.5 \times 10^{4} \mathrm{~mol} / \mathrm{cm}^{3}$ for SIC is proposed. It is coherent with the work of Morrell and Stern, ${ }^{86}$ who investigated SIC through volume changes. In their work, this optimal crosslink density for SIC corresponds roughly to the optimal tensile strength.

For low crosslinked NR, further investigations are required. Indeed, the results obtained by Trabelsi et al., ${ }^{61}$ who showed that SIC is all the more intense that crosslinking is weak, contradict the proposition made by Chenal et al. ${ }^{84}$ who suggested that, below $1.2 \times 10^{4} \mathrm{~mol} / \mathrm{cm}^{3}$, crystallinity rate decreases as crosslink density decreases. Concerning this last point, one should consider the case of unvulcanized NR in which SIC can occur even if the tensile strength is very low. For low crosslink density, the role of entanglements that act as crosslinks should be taken into account and investigated as suggested by Trabelsi et al. ${ }^{61}$

\section{B. CARBON BLACK FILLERS}

The influence of carbon black (CB) fillers on the mechanical response of NR is well known for many years. ${ }^{87-89}$ As shown in Figure 16(a), the addition of carbon black (50 phr in that example) stiffens the material: for a given $\lambda$, the stress is higher in filled rubber than in unfilled one. ${ }^{71}$ The corresponding crystallinity is shown in Figure 16(b). One can see that the onset of crystallization corresponds to a lower value of stretch ratio: $\lambda_{\mathrm{A}} \sim 2$ instead of $\lambda_{\mathrm{A}} \sim 4$ for unfilled rubber. Gehman and Field ${ }^{32}$ already noticed this offset of $\lambda_{\mathrm{A}}$ in CB filled NR. Moreover, the "supercooling effect" is not so important. Based on the former works of Guth and Gold, ${ }^{90}$ and Mullins and Tobin, ${ }^{88}$ Trabelsi et al. ${ }^{71}$ considered that CB fillers lead to an amplification of stress as they locally increase the stretch of macromolecular chains. These authors extended this amplification factor concept to other physical properties such as crystallinity, melting temperature and crystallites size. This amplification effect increases the local strain in the deformable rubber matrix and makes the nucleation of crystallites easier $\left(\lambda_{\mathrm{A}}\right.$ is lower in CB filled rubber). However the maximum crystallinity that can be reached in CB filled NR is lower, partly because the volume fraction of matter that can crystallize is reduced.

Poompradub et al. ${ }^{42}$ studied the stress-strain behavior and the crystallinity evolution for an unfilled NR and two different CB filled NR (one with $20 \mathrm{phr}$ of CB and the other with $40 \mathrm{phr}$ ). They also noticed that SIC starts for lower strain values in CB filled NR. By taking into account the volume fraction of both CB fillers and occluded rubber (supposed to remain undeformed), they suggest that the local strain corresponding to onset of crystallization (denoted $\alpha^{0}$ in their study) is almost the same for the three materials. Chenal et al. ${ }^{63}$ also determined that the local stretch 


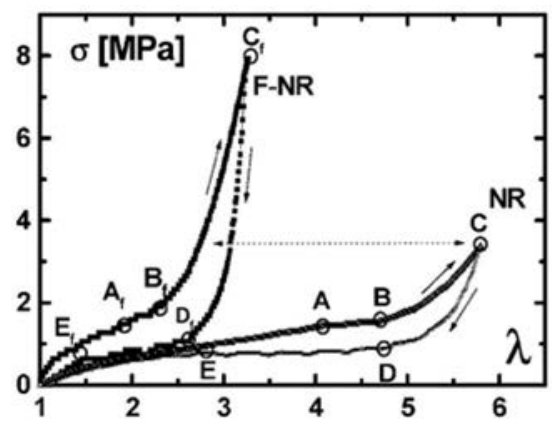

(a)

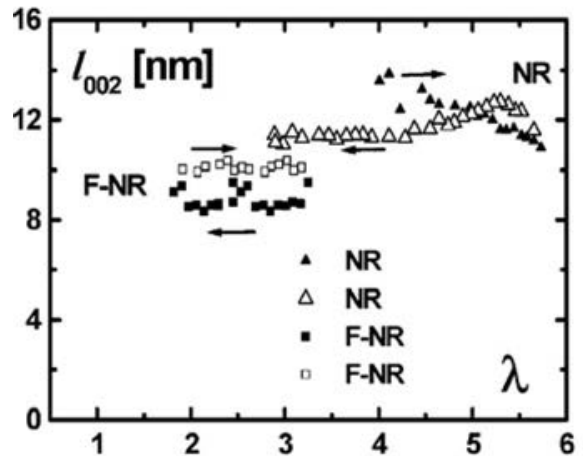

(c)

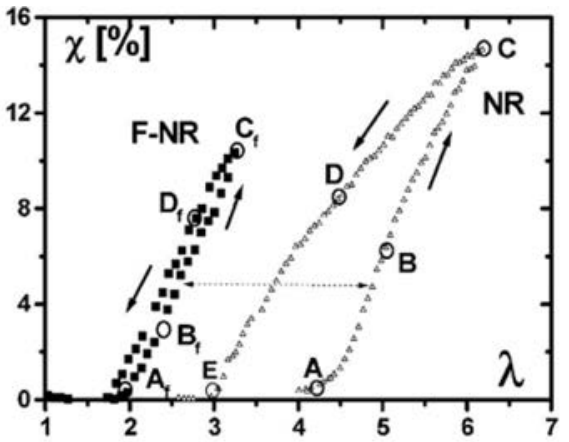

(b)

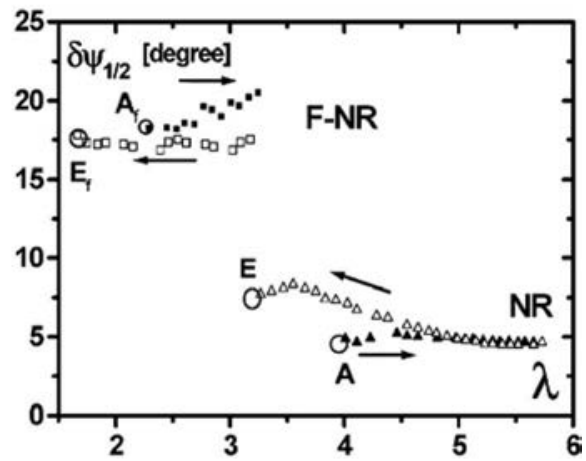

(d)

FIG. 16. - Influence of carbon black fillers ("F-NR" contains $50 \mathrm{phr}$ CB and "NR" is unfilled) on: (a) stress, (b) crystallinity, (c) crystallites size $\left(l_{200}\right)$, and (d) disorientation along $c$-axis vs stretch ratio. (Reprinted from ref 71. Copyright 2003 American Chemical Society.)

ratio for the onset of crystallization of a $45 \mathrm{phr} C B$ filled NR is very close to the macroscopic stretch ratio of an unfilled rubber if one considers the strain amplification effect of fillers.

The crystallites size is slightly smaller with fillers and the disorientation is higher as illustrated in Figures 16(c) and 16(d) ${ }^{71}$ which is rather logical if one considers the reduced mobility of chains in the presence of fillers. The smaller size of NR crystallites with CB fillers was confirmed by Poompradub et al. ${ }^{42}$, who also showed that CB content does not significantly change this size in the range of $20 \mathrm{phr}$ to $40 \mathrm{phr}$. These authors also confirmed the higher disorientation of filled NR compared to unfilled NR. However, the effect of CB fillers on crystallites orientation, as well as on the critical stretch ratio for onset of crystallization, appears less important in their study.

To conclude, $\mathrm{CB}$ fillers reduce the value of the global stretch ratio corresponding to the onset of SIC, which takes place for comparable local stretch ratio in filled and unfilled NR.

\section{TEMPERATURE}

The effect of temperatures below room temperature is not considered in the present review since it involves another phenomenon than SIC, which is the TIC, also called "cold" crystallization. The subject of combined effect of SIC and TIC would require a dedicated review article as it was extensively studied in the past. ${ }^{9,11,12,44,61,75,91}$ Here, only temperatures between room temperature and melting temperature are considered. Many authors have studied the influence of temperature on SIC for NR ${ }^{16,49,53,54,83}$ and IR. ${ }^{75,92}$ All these studies showed that SIC de- 


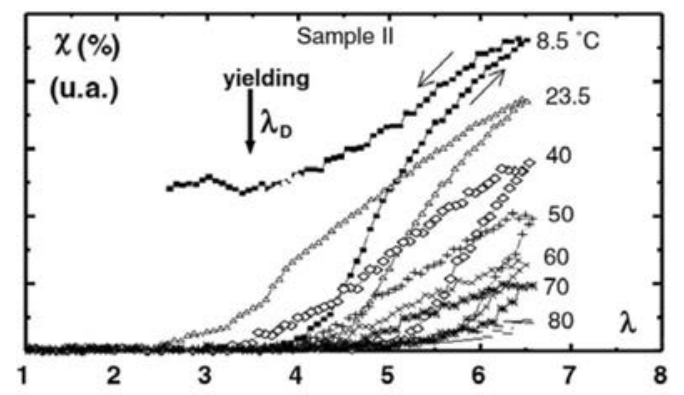

(a)

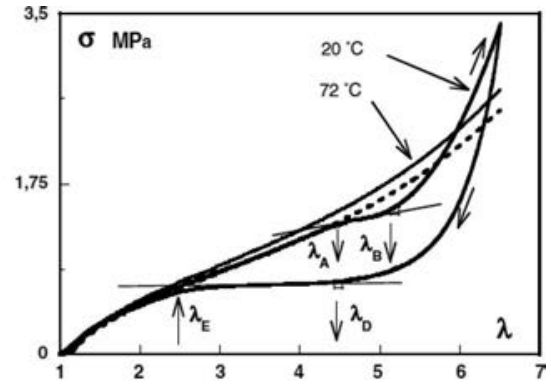

(b)

FIG. 17. - Influence of temperature on: (a) crystallinity vs stretch ratio (NR with $1.2 \mathrm{phr}$ sulfur) and (b) stress-strain curve (NR with $0.8 \mathrm{phr}$ sulfur). (Reprinted with permission from ref 83. Copyright 2005 Springer.)

creases as temperature increases. This was clearly exhibited by Albouy et al. ${ }^{83}$ and Rault et al. ${ }^{16}$, who followed the crystallinity of NR versus stretch ratio for various temperatures. As seen in Figure 17(a), Albouy et al. ${ }^{83}$ showed a regular decrease of SIC with temperature for an unfilled NR and noticed that SIC is almost inexistent at $80{ }^{\circ} \mathrm{C}$. They also showed that temperature affects the stretch ratio for the onset of crystallization $\left(\lambda_{\mathrm{A}}\right)$, which increases with the temperature. These authors also suggested that the influence of temperature on SIC is difficult to take into account through the mechanical response of NR, because temperature has two effects: when it increases, crystallization decreases or even disappears, and on the other way it modifies the behavior of the amorphous phase. Considering this, they tried to evalute the effect of temperature on SIC only, by correcting the mechanical behavior of an unfilled NR. They used the classical stress-strain relationship given by Treloar, ${ }^{93}$ which gives the stress $\sigma$ as a function of temperature

$$
\sigma=n k T\left(\lambda-\frac{1}{\lambda^{2}}\right)
$$

(where $n$ is the number of chains per unit volume, $k$ the Boltzmann constant, $T$ the temperature and $\lambda$ the stretch ratio), to extrapolate the stress at $72{ }^{\circ} \mathrm{C}$; it gives the dashed line in Figure 17(b). They assumed that the difference between this corrected behavior and the response at $20{ }^{\circ} \mathrm{C}$ represents the contribution of SIC. In addition, Rault et al ${ }^{49}$ plotted the stress-strain curves of a NR filled with $20 \mathrm{phr}$ of carbon black for four temperatures and measured simultaneously the crystallinity as a function of stretch ratio (see Figure 18(a), 18(b)). They noticed that both mechanical and crystallinity hysteresis are reduced when temperature increases. These observations confirm the strong correlation between the mechanical behavior of NR and SIC. For the same maximum stretch ratio, the crystallinity decreases from $8 \%$ at $20{ }^{\circ} \mathrm{C}$ to $1 \%$ at 60 ${ }^{\circ} \mathrm{C}$. For this CB filled rubber, the temperature mainly affects the crystallinity rate $(\mathrm{d} \chi / \mathrm{d} \lambda)$. One should note that the mechanical tests presented in Figure 18 are performed at a low displacement rate $(0.035 \mathrm{~mm} / \mathrm{s})$, which corresponds to a strain rate of approximately $10^{-3} \mathrm{~s}^{-1}$. The influence of strain rate has to be considered with care when the effect of the temperature is evaluated (see next section).

Miyamoto et al.$^{92}$ noticed that heating also reduces the crystallinity of unfilled IR during a tension-retraction cycle. In particular, these authors reported the stretch ratio values for both onset of crystallization and completion of melting $\left(\lambda_{\mathrm{A}}\right.$ and $\lambda_{\mathrm{E}}$ respectively, according to Figure $\left.17(\mathrm{~b})\right)$. From 0 to $60{ }^{\circ} \mathrm{C}$, they clearly showed an increase of these two values as well as a decrease of their difference (the so-called "supercooling effect"). 


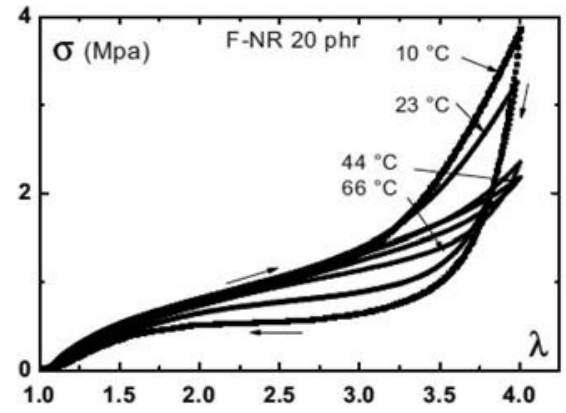

(a)

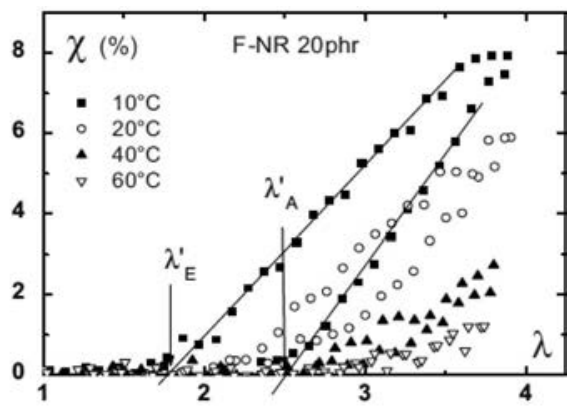

(b)

FIG. 18. - Influence of temperature on: (a) stress-strain curve and (b) crystallinity vs stretch ratio for a filled vulcanized NR (20 phr CB, $1.2 \mathrm{phr}$ sulfur). (Reprinted with permission from ref 49. Copyright 2006 Springer.)

Finally, to the author's knowledge, the effect of temperature in the range of $20-80{ }^{\circ} \mathrm{C}$ on both size and orientation of the crystallites has not been investigated.

\section{STRAIN RATE}

In Section III A, it has been shown that SIC appears very rapidly during stretching. Considering the short time of the delay before crystallization, one can consider that SIC occurs in all the quasi-static tests previously presented, for which strain rate is always smaller than $1 \mathrm{~s}^{-1}$. Nevertheless, during mechanical tests the system is always out of equilibrium even at very low strain rate $\left(10^{-5} \mathrm{~s}^{-1}\right)$, since we have seen that both stress and crystallinity are still evolving after a long time (1 day) during a static test.

Miyamoto et al. ${ }^{92}$ have conducted an extensive study on strain rate influence on IR over four decades (from $7 \times 10^{-4} \mathrm{~s}^{-1}$ to $7 \mathrm{~s}^{-1}$ ). They have demonstrated that the onset of crystallization is shifted from $\lambda=5$ to $\lambda=6$ when the strain rate is multiplied by $10^{4}$.

The effect of strain rate on SIC was also investigated on NR by Trabelsi ${ }^{94}$ and Rault et al ${ }^{49}$ In Figure 19, the plateau $\mathrm{AB}$ appears less distinct for the highest strain rate $\left(5.5 \times 10^{-4} \mathrm{~s}^{-1}\right.$ compared to $4 \times 10^{-5} \mathrm{~s}^{-1}$ ). ${ }^{49}$ Considering their explanation for the stress-strain curve (see Section III D), these authors assumed that SIC kinetics is larger than chains relaxation kinetics. The latter being very low, the chains cannot relax easily for the higher strain rate, and thus the stress increases. In this very low strain rates regime, $\lambda_{\mathrm{A}}$ seems to be the same: strain is assumed to be too slow to delay crystallization. Trabelsi ${ }^{94}$ investigated higher strain rates for tensionretraction tests (from $1.5 \times 10^{-3} \mathrm{~s}^{-1}$ to $5 \times 10^{-2} \mathrm{~s}^{-1}$ ). For these values, the plateau $\mathrm{AB}$ completely disappears and for a given strain (for example, $\lambda=5$ ), the stress during stretch is lower for the higher strain rate. The crystallinity was followed by WAXD and the results showed a small shifting towards higher values for $\lambda_{\mathrm{A}}$. These measurements confirmed that the results obtained by Miyamoto et al. ${ }^{51}$ for IR are also valid for NR. However, the faster SIC kinetics for NR compared to IR reduces this strain rate effect. Trabelsi ${ }^{94}$ also measured a lower crystallinity for the higher strain rate $\left(5 \times 10^{-2} \mathrm{~s}^{-1}\right)$ at a given strain, which explains the lower stress she noticed. In that case, SIC rate would limit the stiffening of rubber. Nevertheless, one must keep in mind that strain rate also influences the mechanical behavior of the amorphous phase.

Finally, considering a quasi-static strain rate in the range of $10^{-3} \mathrm{~s}^{-1}$ as a reference state, it can be said that: 


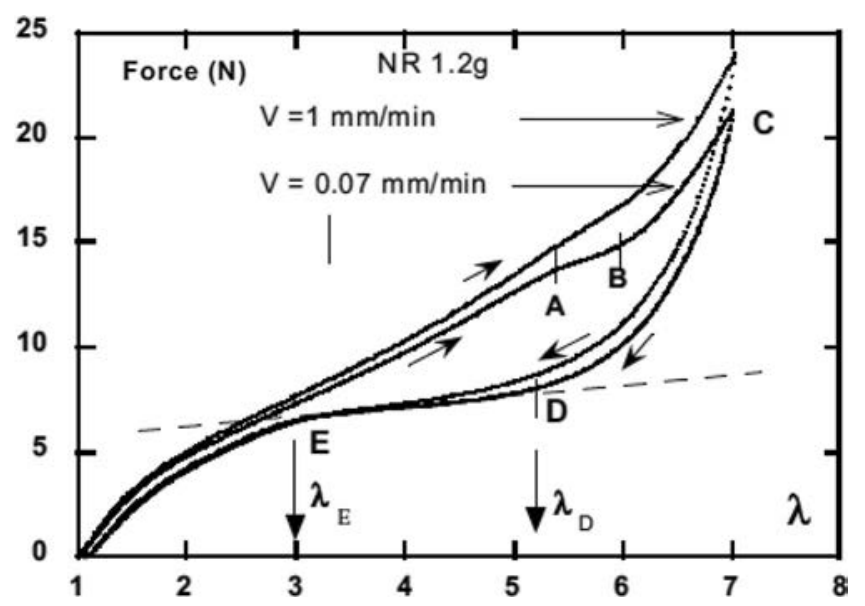

FIG. 19. - Influence of low strain rates on the stress-strain curve of a vulcanized NR (1.2 phr sulfur): $\mathrm{V}=1 \mathrm{~mm} / \mathrm{min}$ and $\mathrm{V}=0.07 \mathrm{~mm} / \mathrm{min}$ corresponding to strain rate of $5.5 \times 10^{-4} \mathrm{~s}^{-1}$ and $4 \times 10^{-5} \mathrm{~s}^{-1}$, respectively. (Reprinted with permission from ref 49 . Copyright 2006 Springer.)

- $\quad$ a reduction in strain rate induces a decrease in the hardening effect of SIC just after $\lambda_{\mathrm{A}}$ because polymer chains can relax, which means that chains relaxation rate is smaller than crystallization rate,

- $\quad$ an increase in strain rate also induces a decrease in the hardening effect of SIC because crystallization is delayed; strain rate becomes larger than crystallization rate, which shifts $\lambda_{\mathrm{A}}$ towards higher values.

The high strain rate regime (above $1 \mathrm{~s}^{-1}$ ) can be considered through the results of the cyclic experiments of Dunning and Pennells ${ }^{54}$ presented in Section III A (see also Figure 4). In particular, a critical strain rate at which SIC disappears can be deduced from the duration of the initial period before SIC starts. As this period is all the more short that $\lambda_{\max }$ is high, the critical strain rate naturally increases with $\lambda_{\max }: \sim 3 \mathrm{~s}^{-1}$ at $\lambda_{\max }=4, \sim 27 \mathrm{~s}^{-1}$ at $\lambda_{\max }=4.5$, and $\sim 80 \mathrm{~s}^{-1}$ at $\lambda_{\max }=5$.

The size and the orientation of crystallites have been investigated by Trabelsi ${ }^{94}$ (strain rates in the range of $1.5 \times 10^{-3}$ to $5 \times 10^{-2} \mathrm{~s}^{-1}$ ) and it seems that they are almost unchanged by the strain rate.

\section{E. FATIGUE}

The fatigue of rubber has been extensively investigated for decades (see, for example, the review articles of Mars and Fatemi ${ }^{95,96}$ ). The first investigations in the 1930s and 1940s showed that NR has remarkable fatigue properties especially in the positive load ratio regime ${ }^{48,97}$ In particular, Cadwell et al. ${ }^{100}$ showed that an increase of $\lambda_{\min }$, for a given $\Delta \lambda$, increases fatigue life. This effect was recently investigated by André et al. ${ }^{98}$ and Saintier et al. ${ }^{99}$ who highlighted it through a Haigh diagram. This phenomenon was also observed by Lindley: ${ }^{100}$ fatigue crack growth rates strongly decrease when $\mathrm{R}$ ratio increases. As all these peculiar properties were only observed on rubbers that crystallize under strain, all these works referred to SIC to explain them. Recently, Mars ${ }^{101}$ showed that a model based on fatigue crack growth characteristics (the power-law slope and the fatigue threshold) can take into account SIC effects and reproduce the Haigh diagram and the Cadwell diagram. Considering all these studies, it is important to quantify SIC for fatigue loading conditions, by using WAXD for example. Despite this fact, such 
experiments are almost inexistent, mainly because the typical frequencies of fatigue tests $(1 \mathrm{~Hz}$ or more) are not compatible with the long time acquisition required by x-ray diffraction. One should cite again the pioneering works of Acken et al. ${ }^{52}$ and Long et al.: ${ }^{53}$ even if their studies were not devoted to fatigue, they were the firsts to use cyclic loading conditions combined to a synchronized exposition to the x-rays at the maximum strain in order to accumulate the weak intensity of the diffracted beam. With this stroboscopic technique, these authors studied the "time lag" necessary for SIC to start (Section III A). This idea was updated in the 1960s by Kawai et al. ${ }^{102}$ who developed an improved version of Acken's initial device to study semi-crystalline polymers. They subsequently used it to study SIC of NR. ${ }^{103,104}$ To the author's knowledge, these studies are the only published ones concerning SIC evolution measured by WAXD during a fatigue test on NR. However, this work is limited to a high $\mathrm{R}$ ratio $\left(\lambda_{\min }=3.5\right.$ and $\left.\lambda_{\max }=4.5\right)$ for which crystallites never melt ( $\lambda_{\min }$ is greater than the critical stretch ratio for crystallites fusion). Kawai ${ }^{104}$ followed the evolution of the diffracted intensities along the equatorial direction, i.e., through the (200) and (120) spots, for the minimal $\left(\lambda_{\min }=3.5\right)$ and the maximal stretch ratio $\left(\lambda_{\max }=4.5\right)$ during $10^{5}$ cycles. SIC appears gradually during the cyclic test while the amorphous halo "degenerates" in the mean time. These changes seem to level off around $10^{3}$ cycles for the maximum strain and around $10^{5}$ cycles for the minimum strain. This author also determined that an increase in frequency (from 0.1 to $10 \mathrm{~Hz}$ ) reduces the degree of crystallinity.

Trabelsi ${ }^{94}$ performed some dynamic cyclic tests and showed that SIC can disappear when the frequency reaches a too high value. She explained the existence of this critical frequency by two effects: (i) the temperature rises which decreases SIC, as seen previously; and (ii) the deformation that takes place faster than crystallization. This critical frequency is between 1 and $10 \mathrm{~Hz}$ for the experimental conditions she considered. It increases as $\lambda_{\max }$ increases (because SIC kinetics is higher) and as $\Delta \lambda$ decreases (because strain rate is lower). For example, when $\Delta \lambda$ $=4.7$ the critical frequency is $1 \mathrm{~Hz}$ for $\lambda_{\max }=5.7$ (strain rate is about $15 \mathrm{~s}^{-1}$ ) and $2 \mathrm{~Hz}$ for $\lambda_{\max }$ $=6.5$ (strain rate is about $30 \mathrm{~s}^{-1}$ ). These values are a little bit smaller compared to the one that can be deduced from the work of Dunning and Pennells: ${ }^{54} \sim 10 \mathrm{~Hz}$ for $\lambda_{\max }=5$ and $\Delta \lambda=4$.

Considering the lack of published studies dealing with SIC during fatigue, further investigations are needed: (i) to explore the evolution of SIC during fatigue, especially when $\lambda_{\min }$ is smaller than the critical stretch ratio for crystallites fusion; (ii) to consider high $\lambda_{\max }$ values that could for example occur at fatigue crack tip. For the latter situation, the critical frequency is expected to be larger than the above-mentioned values. This could possibly explain that the good fatigue resistance of NR, particularly for positive R ratio, is not sensitive to frequency in the usual frequencies range. These investigations should be preferentially carried out on CB filled NR for which most of the fatigue studies had been performed.

\section{F. CRACK TIP}

As it was already emphasized in the introduction of the present article, NR is known to have a very good resistance to crack growth, either in static or in fatigue loading conditions. ${ }^{2,3,96}$

Lee and Donovan ${ }^{105}$ were among the first researchers to investigate the crystallinity at the crack tip of a stretched cut sample by the means of WAXD. For an initial cut of $15 \mathrm{~mm}$ in a $33 \mathrm{~mm}$ width sample of NR vulcanizates, they measured the crystallinity at different distances from crack tip along the direction perpendicular to the stretching direction. Figure 20 shows the crystallinity versus the distance from crack tip for an unfilled and a carbon black filled NR. As expected, the crystallinity strongly increases in the vicinity of the crack tip because of high local stretch ratios. The amplification of the crystallinity due to carbon black fillers, which is clearly seen in Figure 20, is consistent with the one observed in uncut specimens (see Section IV B). 


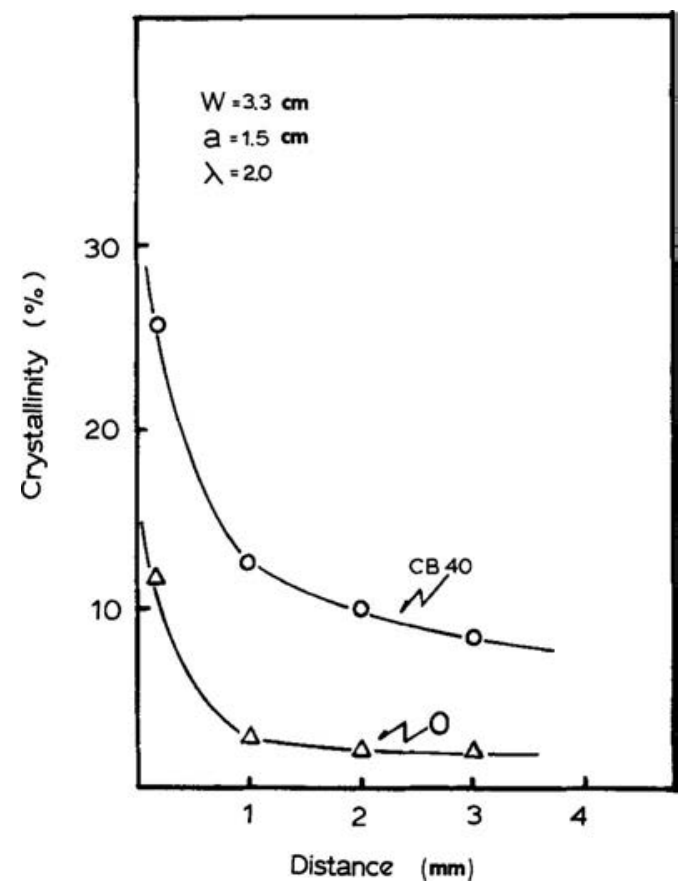

FIG. 20. - Crystallinity as a function of distance from crack tip in unfilled (0) and $40 \mathrm{phr}$ CB filled (CB40) NR at $\lambda$ $=2$. (Reprinted from ref 105. Copyright 1987 Rubber Division, American Chemical Society.)

More recently, Trabelsi et al. ${ }^{106}$ performed an extensive study of the crystallinity all around the crack tip of an unfilled NR sample through contour maps of the crystallinity at room temperature. Figure 21 shows the zone around the tip of a $1 \mathrm{~mm}$ length crack globally stretched to $\lambda=2.1$ (sample width $=8 \mathrm{~mm}$ ). Figure 21(a) represents the stretched sample with the crack tip considered as the origin. Figure 21(b) is a representation of the crack tip, for which the X-axis was dilated: the zone surrounded by the bold line (triangles) represents the region where SIC occurs and is called the crystalline deformed zone (CDZ). It is composed of two regions: the hatched area where the crystallinity remains constant and a transition zone where the crystallinity decreases with the distance from the crack tip and finally disappears around $\mathrm{X}=0.4 \mathrm{~mm}$. Thanks to a calibration curve which gives the crystallinity index $\chi$ versus the stretched ratio $\lambda$, the authors are able to draw iso-values of the local stretch ratios in the so-called CDZ. Figure 21(c) is helpful to visualize the crystallinity index evolution along $\mathrm{X}$-axis for different $\mathrm{Y}$ values. These results are in good agreement with those of Lee and Donovan ${ }^{105}$ except that the latter authors did not detect a homogeneous crystallinity zone. This could be due to the higher spacing they chose between two measurement points (every $1 \mathrm{~mm}$ instead of every $0.05 \mathrm{~mm}$ ). Trabelsi et al. ${ }^{106}$ also studied the influence of the global stretch ratio (in the range of 1.66 to 2.66) on SIC at the crack tip for a 1 $\mathrm{mm}$ long crack. For the lowest values of $\lambda$, no constant crystallinity zone is observed at the crack tip. For $\lambda \geq 2.1$ this zone exists but the maximum crystallinity (about 12\%) does not depend on $\lambda$. Consequently, this value probably represents the maximum crystallinity that can be attained in that rubber.

Finally, NR crack growth resistance in static deformation can be explained by high crystallinity at crack tip. At the moment, no SIC study exists for fatigue cracks. 


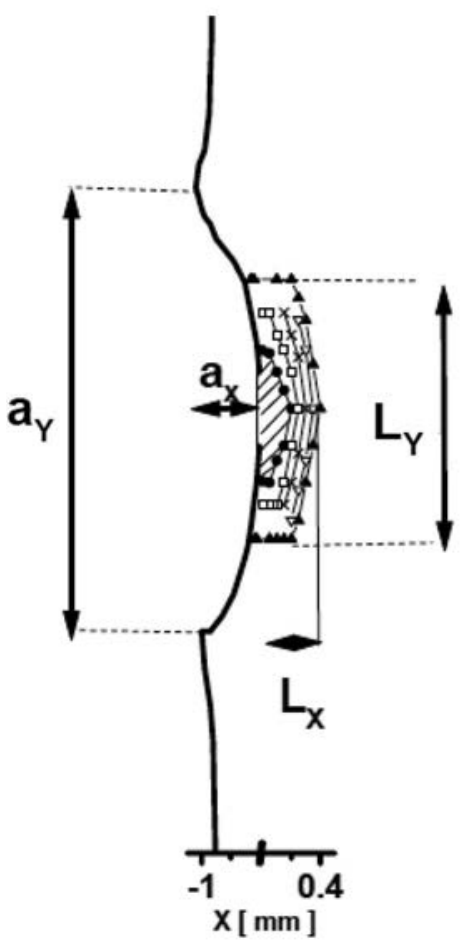

(a)

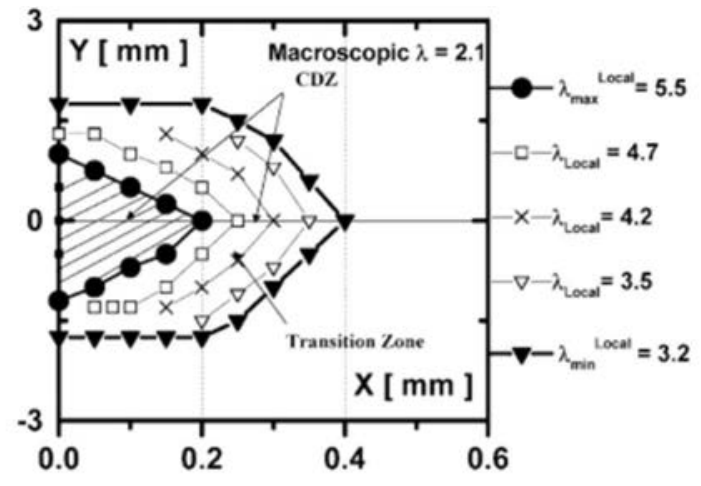

(b)

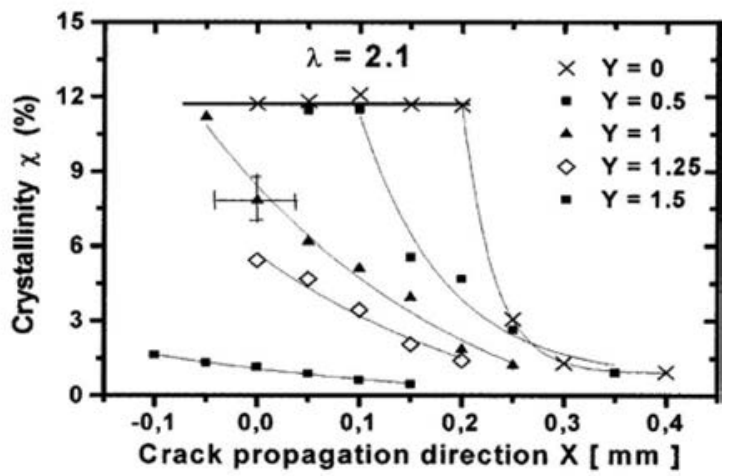

(c)

FIG. 21. - (a) Crack tip region of a stretched $(\lambda=2.1)$ vulcanized NR (1.2 phr sulfur); (b) crystallinity map around the crack tip; (c) crystallinity vs distance from the crack tip at different heights. (Reprinted from ref 106. Copyright 2002 American Chemical Society.)

\section{CONCLUSIONS AND PERSPECTIVES}

For the last 85 years, many studies were devoted to the study of strain-induced crystallization (SIC) of natural rubber (NR) by the means of WAXD. WAXD measurements provide very instructive data to analyze SIC since they give, additionally to the crystallinity, both size and orientation of crystallites.

Part of these investigations was performed to explore the crystalline phase of NR, for example the lattice parameters of the crystal cell; but very rapidly, some researchers focused their work on the relationships between the outstanding mechanical properties of NR and SIC. At the end of this article, the following major conclusions can be drawn:

- When NR is stretched to a stretch ratio greater than a threshold value corresponding to the onset of crystallization (about $\lambda=4$ for unfilled NR, whatever the crosslink density), some of the macromolecules arrange themselves in crystallites presumably composed of fibrillar chains, which are aligned with the stretching direction.

- During static tests, SIC starts almost instantaneously when $\lambda$ is greater than 4 and can continue for days. Crystallization kinetics increases greatly with the maximum stretch ratio $\left(\lambda_{\max }\right)$. SIC is accompanied by a stress decrease due to the relaxation of amorphous chains. 
- During a tension-retraction test, SIC can be studied in real-time by using synchrotron radiation. The major result of such studies is that the mechanical hysteresis of unfilled NR is mainly due to SIC, more precisely to the difference between the stretch ratio at the onset of crystallization and the one at crystallites melting. Moreover, the crystallites size being almost constant during the mechanical cycle, the crystallinity raise is associated with an increase of the number of crystallites.

Many factors affect the SIC of NR: some of them depend on material composition and the other ones depend on experimental conditions:

- As crosslink density increases, the number of crystallites increases and their size decreases. It exists an intermediate crosslink density that maximizes the volume fraction of crystallites and thus the crystallinity. Moreover, the stretch ratio corresponding to the onset of crystallization is roughly independent of the crosslink density.

- Carbon black fillers amplify the local stretch of the chains, which makes SIC start at a lower macroscopic stretch ratio.

- SIC of NR decreases when the temperature increases and it disappears at "high" temperatures (above $80{ }^{\circ} \mathrm{C}$ for unfilled NR).

- $\quad$ NR is not very sensitive to strain rate compared to other crystallizable rubbers such as IR, because the early stages of SIC are fast. However, the hardening effect of SIC is diminished at very low strain rates (lower than $10^{-3} \mathrm{~s}^{-1}$ ) because the slow kinetics of chains relaxation counterbalances it by decreasing the stress; at high strain rates (from 1 $\mathrm{s}^{-1}$ to $100 \mathrm{~s}^{-1}$, depending on $\lambda_{\max }$ ) SIC disappears because its kinetics is slower than strain rate.

- In fatigue, the influence of raising frequencies that can lower SIC has to be considered by the increase of both temperature and strain rate. The critical frequency at which SIC disappears increases with $\lambda_{\max }$ (higher SIC kinetics) and as $\Delta \lambda$ decreases (lower strain rate).

- Finally, crack growth resistance of NR is correlated with a high crystallinity at the crack tip, due to high strain level.

Some perspectives for WAXD investigations of SIC are suggested, mainly for filled NR:

- Fatigue cracks should be studied and correlated to fatigue crack growth rates, probably by using synchrotron radiation to follow SIC along fatigue life.

- Multiaxial loading conditions should also be considered to take into account the complex strain field that exists in industrial parts.

For such conditions, the mechanisms of SIC will be probably different from those described in the present review: the high strain level reached at the crack tip could increase the critical frequency at which SIC disappears, and the multiaxial loading will surely modify the crystallites formation and their orientation.

These future experimental investigations are all the more important that current modeling and simulation works are dedicated to constitutive models and end-of-life criteria for industrial parts submitted to complex multiaxial and/or fatigue loadings.

\section{ACKNOWLEDGMENTS}

The author would like to thank E. Verron, S. Beurrot, and W.V. Mars for fruitful discussions on the subject.

\section{REFERENCES}

${ }^{1}$ G. J. Lake and A. G. Thomas, "Engineering with Rubber - How to Design Rubber Components," Chapter 5, A. N. Gent, Ed., Carl Hanser Verlag, Munich, 2001. 
${ }^{2}$ G. J. Lake, RubBer CHEM. TECHNOL. 68, 435 (1995).

${ }^{3}$ G. R. Hamed, H. J. Kim, and A. N. Gent, Rubber Chem. Technol. 69, 807 (1996).

${ }^{4}$ Y. Tanaka and L. Tarachiwin, RuBBER CHEM. TECHNOL. 82, 283 (2009).

${ }^{5}$ Y. Tanaka, RubBer CHEM. TECHNOL. 74, 355 (2001).

${ }^{6}$ J. R. Katz, Naturwiss. 13, 410 (1925).

${ }^{7}$ N. Bekkedahl and L. A. Wood, Ind. Eng. Chem. 33, 381 (1941).

${ }^{8}$ L. A. Wood and N. Bekkedahl, J. Appl. Phys. 17, 362 (1946).

${ }^{9}$ A. N. Gent, Trans. Faraday Soc. 50, 521 (1954).

${ }^{10}$ J.-B. Le Cam, Rubber Chem. TeChnol. 83, 247 (2010).

${ }^{11}$ E. H. Andrews, Pure Appl. Chem. 31, 91 (1972).

${ }^{12}$ D. Luch and G. S. Y. Yeh, J. Appl. Phys. 43, 4326 (1972).

${ }^{13}$ D. Goritz and R. Grassler, RuBBer CHEM. TECHNOL. 60, 217 (1987).

${ }^{14}$ L. R. G. Treloar, Trans. Faraday Soc. 37, 84 (1941).

${ }^{15}$ M. Tosaka, S. Kohjiya, Y. Ikeda, S. Toki, and B. S. Hsiao, Polym. J. 42, 474 (2010).

${ }^{16}$ J. Rault, J. Marchal, P. Judeinstein, and P. A. Albouy, Macromolecules 39, 8356 (2006).

${ }^{17}$ A. M. Healey, P. J. Hendra, and Y. D. West, Polymer 37, 4009 (1996).

${ }^{18}$ P. J. Flory, "Principles of Polymer Chemistry," Cornell University Press, Ithaca, 1953.

${ }^{19}$ L. R. G. Treloar, "The Physics of Rubber Elasticity,” Oxford University Press, Oxford, 1975.

${ }^{20}$ D. E. Roberts and L. Mandelkern, J. Am. Chem. Soc. 77, 781 (1955).

${ }^{21}$ J. H. Magill, RubBer Chem. TeChnOL. 68, 507 (1995).

${ }^{22}$ M. Tosaka, Polym. J. 39, 1207 (2007).

${ }^{23}$ M. Tosaka, S. Kohjiya, S. Murakami, S. Poompradub, Y. Ikeda, S. Toki, I. Sics, and B. S. Hsiao, RubBER CHEM. TECHNOL. 77, 711 (2004).

${ }^{24}$ H. Mark and G. von Susich, Kolloid-Z. 46, 11 (1928).

${ }^{25}$ K. H. Meyer and H. Mark, Ber. Dtsch. Chem. Ges. 61, 1939 (1928).

${ }^{26}$ W. Lotmar and K. H. Meyer, Monatsh. Chem. 69, 115 (1936).

${ }^{27}$ E. Sauter, Z. Phys. Chem. B-Chem. Elem. Aufbau. Mater. 36, 405 (1937).

${ }^{28}$ H. A. Morss, J. Am. Chem. Soc. 60, 237 (1938).

${ }^{29}$ G. L. Clark, Ind. Eng. Chem. 31, 1397 (1939).

${ }^{30}$ S. D. Gehman, Chem. Rev. 26, 203 (1940).

${ }^{31}$ S. D. Gehman and J. E. Field, J. Appl. Phys. 10, 564 (1939).

${ }^{32}$ S. D. Gehman and J. E. Field, Ind. Eng. Chem. 32, 1401 (1940).

${ }^{33}$ C. W. Bunn, Proc. R. Soc. London, Ser. A 180, 40 (1942).

${ }^{34}$ S. C. Nyburg, Acta Crystallogr. 7, 385 (1954).

${ }^{35}$ G. Natta and P. Corradini, Angew. Chem. 68, 615 (1956).

${ }^{36}$ G. R. Mitchell, Polymer 25, 1562 (1984).

${ }^{37}$ Y. Takahashi and T. Kumano, Macromolecules 37, 4860 (2004).

${ }^{38}$ A. Immirzi, C. Tedesco, G. Monaco, and A. E. Tonelli, Macromolecules 38, 1223 (2005).

${ }^{39}$ G. Rajkumar, J. M. Squire, and S. Arnott, Macromolecules 39, 7004 (2006).

${ }^{40}$ S. Arnott and A. J. Wonacott, Polymer 7, 157 (1966).

${ }^{41}$ S. Poompradub, M. Tosaka, S. Kohjiya, Y. Ikeda, S. Toki, I. Sics, and B. S. Hsiao, Chem. Lett. 33, 220 (2004).

${ }^{42}$ S. Poompradub, M. Tosaka, S. Kohjiya, Y. Ikeda, S. Toki, I. Sics, and B. S. Hsiao, J. Appl. Phys. 97, 103529 (2005).

${ }^{43}$ E. H. Andrews, Proc. R. Soc. London, Ser. A 270, 232 (1962).

${ }^{44}$ E. H. Andrews, Proc. R. Soc. London, Ser. A 277, 562 (1964). 
${ }^{45}$ T. Shimizu, M. Tosaka, M. Tsuji, and S. Kohjiya, RubBer CheM. TeCHnOL. 73, 926 (2000).

${ }^{46}$ D. Luch and G. S. Y. Yeh, J. Macromol. Sci., Part B: Phys. B 7, 121 (1973).

${ }^{47}$ S. Toki, T. Fujimaki, and M. Okuyama, Polymer 41, 5423 (2000).

${ }^{48}$ W. F. Busse, Ind. Eng. Chem. 26, 1194 (1934).

${ }^{49}$ J. Rault, J. Marchal, P. Judeinstein, and P. A. Albouy, Eur. Phys. J. E: Soft Matter Biol. Phys. 21, 243 (2006).

${ }^{50}$ I. S. Choi and C. M. Roland, RubBer CheM. TeChnOL. 70, 202 (1997).

${ }^{51}$ M. Tosaka, D. Kawakami, K. Senoo, S. Kohjiya, Y. Ikeda, S. Toki, and B. S. Hsiao, Macromolecules 39, 5100 (2006).

${ }^{52}$ M. F. Acken, W. E. Singer, and W. P. Davey, Ind. Eng. Chem. 24, 54 (1932).

${ }^{53}$ J. D. Long, W. E. Singer, and W. P. Davey, Ind. Eng. Chem. 26, 543 (1934).

${ }^{54}$ D. J. Dunning and P. J. Pennells, RubBer Chem. TeChnOL. 40, 1381 (1967).

${ }^{55}$ J. C. Mitchell and D. J. Meier, J. Polym. Sci., Part A-2: Polym. Phys. 6, 1689 (1968).

${ }^{56}$ M. P. Votinov, S. A. Subbotin, V. V. Samoletova, S. P. Konytovskaya, and E. V. Kuvshinskii, RubBER CHEM. TECHNOL. 33, 988 (1960).

${ }^{57}$ J. E. Field, J. Appl. Phys. 12, 23 (1941).

${ }^{58}$ J. M. Goppel and J. J. Arlman, Appl. Sci. Res., Sect. A 1, 462 (1949).

${ }^{59}$ S. C. Nyburg, Br. J. Appl. Phys. 5, 321 (1954).

${ }^{60}$ L. E. Alexander, S. Ohlberg, and G. R. Taylor, J. Appl. Phys. 26, 1068 (1955).

${ }^{61}$ S. Trabelsi, P. A. Albouy, and J. Rault, Macromolecules 36, 7624 (2003).

${ }^{62}$ E. A. Hauser and H. Mark, Kolloidchem. Beih. 22, 63 (1926).

${ }^{63}$ J. M. Chenal, C. Gauthier, L. Chazeau, L. Guy, and Y. Bomal, Polymer 48, 6893 (2007).

${ }^{64}$ I. Williams and B. M. Sturgis, Ind. Eng. Chem. 31, 1303 (1939).

${ }^{65}$ G. L. Clark, M. Kabler, E. Blaker, and J. M. Ball, Ind. Eng. Chem. 32, 1474 (1940).

${ }^{66}$ L. R. G. Treloar, Trans. Faraday Soc. 43, 284 (1947).

${ }^{67}$ P. A. Thiessen and W. Wittstadt, RubBER CHEM. TECHNOL. 12, 736 (1939).

${ }^{68}$ S. Murakami, K. Senoo, S. Toki, and S. Kohjiya, Polymer 43, 2117 (2002).

${ }^{69}$ S. Toki, I. Sics, S. F. Ran, L. Z. Liu, B. S. Hsiao, S. Murakami, K. Senoo, and S. Kohjiya, Macromolecules 35, 6578 (2002).

${ }^{70}$ S. Toki, I. Sics, S. F. Ran, L. Z. Liu, and B. S. Hsiao, Polymer 44, 6003 (2003).

${ }^{71}$ S. Trabelsi, P. A. Albouy, and J. Rault, Macromolecules 36, 9093 (2003).

${ }^{72}$ M. Tosaka, S. Murakami, S. Poompradub, S. Kohjiya, Y. Ikeda, S. Toki, I. Sics, and B. S. Hsiao, Macromolecules 37, 3299 (2004).

${ }^{73}$ S. Toki, I. Sics, S. F. Ran, L. Z. Liu, B. S. Hsiao, S. Murakami, M. Tosaka, S. Kohjiya, S. Poompradub, Y. Ikeda, and A. H. Tsou, Rubber Chem. Technol. 77, 317 (2004).

${ }^{74}$ S. Toki, I. Sics, B. S. Hsiao, S. Murakami, M. Tosaka, S. Poompradub, S. Kohjiya, and Y. Ikeda, J. Polym. Sci., Part B: Polym. Phys. 42, 956 (2004).

${ }^{75}$ S. Toki, I. Sics, B. S. Hsiao, M. Tosaka, S. Poompradub, Y. Ikeda, and S. Kohjiya, Macromolecules 38, 7064 (2005). ${ }^{76}$ S. Toki, B. S. Hsiao, S. Kohjiya, M. Tosaka, A. H. Tsou, and S. Datta, Rubber ChEM. TeChnOL. 79, 460 (2006).

${ }^{77}$ S. Toki, I. Sics, C. Burger, D. F. Fang, L. Z. Liu, B. S. Hsiao, S. Datta, and A. H. Tsou, Macromolecules 39, 3588 (2006).

${ }^{78}$ S. Kohjiya, M. Tosaka, F. Masahiro, Y. Ikeda, S. Toki, and B. S. Hsiao, Polymer 48, 3801 (2007).

${ }^{79}$ S. Toki, N. Minouchi, I. Sics, B. S. Hsiao, and S. Kohjiya, Kautsch. Gummi Kunstst. 61, 85 (2008).

${ }^{80}$ S. Amnuaypornsri, J. Sakdapipanich, S. Toki, B. S. Hsiao, N. Ichikawa, and Y. Tanaka, RubBER ChEM. TECHNOL. 81, 753 (2008).

${ }^{81}$ S. Toki, C. Burger, B. S. Hsiao, S. Amnuaypornsri, J. Sakdapipanich, and Y. Tanaka, J. Polym. Sci., Part B: Polym. Phys. 46, 2456 (2008). 
${ }^{82}$ S. Trabelsi, P. A. Albouy, and J. Rault, RubBer ChEM. TEChnOL. 77, 303 (2004).

${ }^{83}$ P. A. Albouy, J. Marchal, and J. Rault, Eur. Phys. J. E: Soft Matter Biol. Phys. 17, 247 (2005).

${ }^{84}$ J. M. Chenal, L. Chazeau, L. Guy, Y. Bomal, and C. Gauthier, Polymer 48, 1042 (2007).

${ }^{85}$ S. Ran, D. Fang, X. Zong, B. S. Hsiao, B. Chu, and P. M. Cunniff, Polymer 42, 1601 (2001).

${ }^{86}$ S. H. Morrell and J. Stern, RubBer ChEM. TEChNOL. 26, 17 (1953).

${ }^{87}$ E. Guth, J. Appl. Phys. 16, 20 (1945).

${ }^{88}$ L. Mullins and N. R. Tobin, J. Appl. Polym. Sci. 9, 2993 (1965).

${ }^{89}$ J. A. C. Harwood and A. R. Payne, J. Appl. Polym. Sci. 10, 315 (1966).

${ }^{90}$ E. Guth and O. Gold, Phys. Rev. 53, 322 (1938).

${ }^{91}$ G. S. Y. Yeh, Polym. Eng. Sci. 16, 145 (1976).

${ }^{92}$ Y. Miyamoto, H. Yamao, and K. Sekimoto, Macromolecules 36, 6462 (2003).

${ }^{93}$ L. R. G. Treloar, Trans. Faraday Soc. 39, 36 (1943).

${ }^{94}$ S. Trabelsi, "Etude statique et dynamique de la cristallisation des élastomères sous tension," PhD Thesis (in French), Paris XI University, Orsay, 2002.

${ }^{95}$ W. V. Mars and A. Fatemi, Int. J. Fatigue 24, 949 (2002).

${ }^{96}$ W. V. Mars and A. Fatemi, RubBer Chem. TeChNOL. 77, 391 (2004).

${ }^{97}$ S. Cadwell, R. Merrill, C. Sloman, and F. Yost, Ind. Eng. Chem. 12, 19 (1940).

${ }^{98}$ N. André, G. Cailletaud, and R. Piques, Kautsch. Gummi Kunstst. 52, 120 (1999).

${ }^{99}$ N. Saintier, G. Cailletaud, and R. Piques, Int. J. Fatigue 28, 530 (2006).

${ }^{100}$ P. B. Lindley, Int. J. Fract. 9, 449 (1973).

${ }^{101}$ W. V. Mars, RubBer CHEM. TeChnOL. 82, 51 (2009).

${ }^{102}$ H. Kawai, D. A. Keedy, R. S. Stein, and T. Itoh, J. Polym. Sci., Part B: Polym. Lett. 2, 1075 (1964).

${ }^{103}$ H. Hiratsuka, M. Hashiyama, S. Tomita, and H. Kawai, J. Macromol. Sci., Part B: Phys. 8, 101 (1973).

${ }^{104}$ H. Kawai, Rheol. Acta 14, 27 (1975).

${ }^{105}$ D. J. Lee and J. A. Donovan, RubBer CHEM. TEChnOL. 60, 910 (1987).

${ }^{106}$ S. Trabelsi, P. A. Albouy, and J. Rault, Macromolecules 35, 10054 (2002). 